\title{
Mesenchymal stem cells induce tumor stroma formation and epithelial-mesenchymal transition through SPARC expression in colorectal cancer
}

\author{
TOSHIKATSU NAITO ${ }^{1}$, RYO YUGE ${ }^{2}$, YASUHIKO KITADAI ${ }^{3}$, HIDEHIKO TAKIGAWA ${ }^{1}$, YUKIHITO HIGASHI ${ }^{4}$, \\ TOSHIO KUWAI ${ }^{5}$, KAZUYA KURAOKA ${ }^{6}$, SHINJI TANAKA $^{2}$ and KAZUAKI CHAYAMA ${ }^{1}$ \\ Departments of ${ }^{1}$ Gastroenterology and Metabolism, and ${ }^{2}$ Endoscopy and Medicine, Hiroshima University, \\ Hiroshima 734-8551; ${ }^{3}$ Department of Health Science, Prefectural University of Hiroshima, \\ Hiroshima 734-8558; ${ }^{4}$ Department of Cardiovascular Physiology and Medicine, \\ Hiroshima University, Hiroshima 734-8551; Departments of ${ }^{5}$ Gastroenterology and \\ ${ }^{6}$ Pathology, National Hospital Organization Kure Medical Center, Hiroshima 737-0023, Japan
}

Received October 25, 2020; Accepted February 9, 2021

DOI: $10.3892 /$ or.2021.8055

\begin{abstract}
Tumor-stroma interactions serve a crucial role in the development of colorectal cancer (CRC), in which secreted protein acidic and rich in cysteine (SPARC) has been implicated. Due to interactions between cancer and stromal cells [mesenchymal stem cells (MSCs)], SPARC gene expression is markedly upregulated in CRC cells. The present study investigated the role of SPARC in CRC development and its potential as a biomarker. Specifically, the present study examined the association between SPARC expression and clinicopathological characteristics in 42 cases of CRC. SPARC expression in cancer cells was associated with $\mathrm{T}$ grade, $\mathrm{N}$ grade (TNM classification), stage and poor prognosis. Furthermore, the area of fibroblast-activating protein-positive staining around the cancer cells was increased in SPARC-positive compared with SPARC-negative cases. Proliferation and wound healing assays in SPARC-silenced KM12SM cells [short hairpin RNA SPARC (shSPARC)], the reduced SPARC expression of which was demonstrated by reverse transcription-quantitative PCR, revealed that the proliferative and migratory capacity of shSPARC cells did not differ from that of wild-type (WT) cells. However, it was markedly reduced when co-cultured with MSCs. Furthermore, in vivo, immunohistological analysis and
\end{abstract}

Correspondence to: Dr Ryo Yuge, Department of Endoscopy and Medicine, Hiroshima University, 1-2-3, Kasumi, Minami-ku, Hiroshima 734-8551, Japan

E-mail: makapoo@hiroshima-u.ac.jp

Abbreviations: CAF, carcinoma-associated fibroblast; EMT, epithelial-mesenchymal transition; GFP, green fluorescent protein; GSEA, gene set enrichment analysis; MSCs, mesenchymal stem cells; SPARC, secreted protein acidic and rich in cysteine; WT, wild-type

Key words: SPARC, EMT, colorectal cancer, orthotopic nude mouse model, tumor microenvironment
RNA sequencing were conducted in an orthotopic implanted mouse model. Tumor growth and lymph node metastasis were markedly suppressed in shSPARC-transplanted tumors compared with WT-transplanted tumors, with a more marked suppression observed following shSPARC co-transplantation with MSCs. Immunohistological examination further revealed that the stromal reaction and epithelial-mesenchymal transition (EMT) were markedly suppressed in tumors co-transplanted with shSPARC and MSCs, and these results were consistent with RNA sequencing using RNA extracted from orthotopic tumors. Overall, these results suggested that SPARC expression in CRC cells is dependent on the interaction between cancer cells and stromal cells to induce EMT and promote stromal formation in the tumor microenvironment, suggesting its suitability as a novel target molecule for CRC treatment.

\section{Introduction}

Colorectal cancer (CRC) is the third most common type of cancer worldwide, and the fourth leading cause of cancer-associated mortality (1). Between 1 and 2 million new CRC cases were diagnosed annually between 2012 and 2016, and $>700,000$ individuals with CRC died each year between 2012 and 2016 (2). Despite improved diagnostic and therapeutic methods, the prognosis of CRC remains poor, primarily due to local recurrence and distant metastasis (3). Therefore, a more detailed understanding of the factors involved in the development and progression of $\mathrm{CRC}$ is required to identify novel biomarkers and to develop novel anticancer strategies.

Tumors are not solely composed of cancer cells but also contain a tumor stroma comprising cellular components, such as fibroblasts, smooth muscle cells, vascular cells (vascular endothelial cells and pericytes), inflammatory cells, and an extracellular matrix (ECM) containing cytokines and cellular growth factors (4). Although cancer is caused by the accumulation of genetic abnormalities in epithelial cells, accumulating evidence has demonstrated that tumor growth 
and metastasis are not only associated with the characteristics of tumor cells but also with their interactions with stromal cells $(5,6)$. In CRC, following infiltration of the submucosal tissue by cancer cells, stromal fibroblasts proliferate around the tumor nest in a process referred to as 'stromal reaction' (7). Carcinoma-associated fibroblasts (CAFs) are the main component of this fibrous stroma (8). The interaction between CAFs and cancer cells is hypothesized to function as a promoter of tumor growth and development (9).

Tumor-associated stromal cells, such as CAFs, are a key component of the tumor microenvironment and interact with cancer cells, resulting in the production of regulatory growth factors and cytokines (10). CAFs are considered to originate from mesenchymal stem cells (MSCs), which migrate into the tumor stroma and differentiate into CAFs to form the tumor stroma (11). Furthermore, epithelial-mesenchymal transition (EMT) is promoted in cancer cells via direct contact with stromal cells (12). EMT is a key developmental process, which is often activated during cancer cell invasion and metastasis, and enables cancer cells to disseminate from a primary tumor by losing their epithelial characteristics, acquiring a mesenchymal phenotype and promoting tumor progression by activating the tumor stroma (13). However, to the best of our knowledge, the specific genes involved in the process of tumor development and formation of the tumor microenvironment through these cancer-stroma interactions have not yet been investigated in detail.

Our previous study investigated the interactions between cancer cells and the tumor stroma during CRC tumor development, and it was reported that MSCs migrate to the tumor stroma where they differentiate into CAFs to promote tumor growth and development (11). Furthermore, one of our previous studies examined the effects of MSCs on cancer cells and revealed that the expression levels of secreted protein acidic and rich in cysteine (SPARC), pentraxin 3 (PTX3), fibronectin $1(F N 1)$, follistatin-related protein 1 (FSTL1) and galectin 1 (LGALS1) were upregulated in direct contact co-cultures of the KM12SM CRC cell line and MSCs (12). Among these, SPARC was the most markedly upregulated gene. SPARC, an ECM glycoprotein with a molecular weight of $32 \mathrm{kDa}$, has a number of functions, including tissue remodeling, wound repair, and cell migration and differentiation (14). Although SPARC is expressed in various types of cancer, its expression pattern and effects on patient prognosis differ among cancer types (15-17). In CRC, conflicting results have been reported regarding the association between SPARC expression and patient prognosis $(18,19)$; however, no detailed reports regarding its function have been provided. Therefore, the present study investigated the association between SPARC expression and clinicopathological factors in human CRC tissues. Furthermore, the present study used an orthotopic transplant murine model to investigate the effect of SPARC expression induced by direct contact between cancer cells and MSCs on the tumor microenvironment.

\section{Materials and methods}

Patients and surgical specimens. Archival formalin-fixed, paraffin-embedded tumor tissues were obtained from the National Hospital Organization Kure Medical Center (Hiroshima, Japan). Tissue samples collected from all
42 patients [age range, 47-89 years; median age, 71 years; 23 male $(55 \%)$ and 19 female (45\%) patients] with colon dysplasia and cancer who underwent surgical resection at the National Hospital Organization Kure Medical Center (Hiroshima, Japan) between January 2011 and October 2013 were examined using immunohistochemistry. Tumor staging was performed according to the TNM classification system of the Japanese general rules for clinical and pathological studies on cancers of the colon, rectum and anus. Patient anonymity, as described by the Ethical Guidelines for Human Genome/Gene Research of the Japanese Government (20), was ensured, and no personally identifiable information was attached to the tissue samples before analysis.

Reagents. The following primary antibodies were used in the present study: Polyclonal goat anti-SPARC (dilution, 1:100; cat. no. AF941; R\&D Systems, Inc.), monoclonal rat anti-PTX3 (dilution, 1:500; cat. no. ab90806; Abcam), monoclonal mouse anti-fibronectin ( $\mathrm{FN}$; for surgical specimens; dilution, 1:200; cat. no. ab6328; Abcam), polyclonal rabbit anti-FSTL1 (dilution, 1:200; cat. no. 20182-1-AP; ProteinTech Group, Inc.), polyclonal rabbit anti-LGALS1 (dilution, 1:100; cat. no. ab25138; Abcam), polyclonal rabbit anti-fibroblast activation protein (FAP; dilution, 1:100; cat. no. ab53066; Abcam), rat anti-mouse CD31 (dilution, 1:50; cat. no. 550274; BD Pharmingen; BD Biosciences), anti-lymphatic vessel endothelial hyaluronan receptor 1 (Lyve 1; dilution, 1:20; cat. no. AF2125; R\&D Systems, Inc.), rabbit anti- $\alpha$-smooth muscle actin ( $\alpha$-SMA; dilution, 1:200; cat. no. ab5694; Abcam), polyclonal rabbit anti-mouse type I collagen (dilution, 1:500; cat. no. 20151; Novotec), Ki-67 equivalent (dilution, 1:1,000; cat. no. ACK02; Novocastra; Leica Microsystems, Ltd.), anti-E-cadherin (dilution, 1:100; cat. no. sc-7870; Santa Cruz Biotechnology, Inc.) and anti-FN (for implanted tumor; dilution, 1:100; cat. no. sc-6952; Santa Cruz Biotechnology, Inc.). The fluorescent secondary antibodies were: Alexa Fluor 488 E-conjugated goat anti-rabbit IgG (dilution, 1:500; cat. no. A11034; Invitrogen; Thermo Fisher Scientific, Inc.), Alexa Fluor 568 E-conjugated goat anti-rat IgG (dilution, 1:500; cat. no. A11077; Invitrogen; Thermo Fisher Scientific, Inc.), Alexa Fluor 546 E-conjugated goat anti-rabbit IgG (dilution, 1:500; cat. no. A11035; Invitrogen; Thermo Fisher Scientific, Inc.) and Alexa Fluor 568 E-conjugated donkey anti-goat IgG (dilution, 1:500; cat. no. A11057; Invitrogen; Thermo Fisher Scientific, Inc.).

Human CRC cell line and culture conditions. The KM12SM cell line (21), a highly metastatic human CRC clonal cell line selected from the parental KM12C cell line, was donated by Dr Isaiah J. Fidler (University of Texas, Houston, TX, USA). DMEM (cat. no. D6046; Sigma-Aldrich; Merck KGaA) supplemented with $10 \%$ FBS (Sigma-Aldrich; Merck KGaA) and 1\% penicillin-streptomycin mixture was used to culture the cell line, and cells were incubated at $37^{\circ} \mathrm{C}$ in a $5 \% \mathrm{CO}_{2}$-humidified atmosphere. Following their recovery from frozen stock $\left(-196^{\circ} \mathrm{C}\right)$, cells were cultured for $\leq 12$ weeks.

Stable transfection and selection of KM12SM cells expressing green fluorescent protein (GFP). KM12SM CRC cells were transfected with GFP and puromycin-resistance genes using 
copGFP control lentiviral particles (cat. no. sc-108084; Santa Cruz Biotechnology, Inc.) according to the manufacturer's protocol. This product was a ready-to-use virus particle (3rd generation packaging system), and $200 \mu \mathrm{l}$ viral stock contained $1 \times 10^{6}$ infectious units of virus (IFU). Cells were cultured in a 12-well plate in medium (DMEM supplemented with $10 \%$ FBS and $1 \%$ penicillin-streptomycin mixture) to $50 \%$ confluence. After $24 \mathrm{~h}$, media were removed and then substituted with $1 \mathrm{ml}$ medium containing polybrene (cat. no. sc-134220; Santa Cruz Biotechnology, Inc.) at a final concentration of $5 \mu \mathrm{g} / \mathrm{ml}$. Cells were infected by adding $20 \mu \mathrm{l}$ (0.5 MOI) of the lentiviral particles to the culture, mixed by swirling and incubated at $37^{\circ} \mathrm{C}$ in a $5 \% \mathrm{CO}_{2}$-humidified atmosphere overnight. At $24 \mathrm{~h}$ after infection, polybrene-containing medium was removed and fresh medium (without polybrene) was added. The cell populations present at $48 \mathrm{~h}$ after infection were then incubated in DMEM supplemented with $10 \%$ FBS and $1 \%$ penicillin-streptomycin mixture containing the appropriate antibiotic $(10 \mu \mathrm{g} / \mathrm{ml}$ puromycin) for an additional 2 weeks. The cells selected $>2$ weeks after transduction were used for subsequent experimentation.

Human MSC isolation and cultivation. MSCs were provided by Dr Yukihito Higashi (Department of Cardiovascular Physiology and Medicine, Hiroshima University, Hiroshima, Japan), and details of MSC isolation and cultivation were as described subsequently. Bone marrow was aspirated from the iliac crest of a 24-year-old male patient with Buerger's disease who underwent BM-mononuclear cells (BM-MNCs) implantation at Hiroshima University Hospital (Hiroshima, Japan) on June 3, 2015. Written informed consent was obtained from the donor. BM-MNCs were isolated using centrifugation at $18,000 \mathrm{x} \mathrm{g}$ at $4^{\circ} \mathrm{C}$ for $30 \mathrm{~min}$ through a Histopaque density gradient (Sigma-Aldrich; Merck KGaA) as previously described (22). To obtain autologous MSCs, BM-MNCs were seeded on plastic culture dishes in DMEM supplemented with 10\% FBS, 4 mM L-glutamine and 1\% penicillin-streptomycin mixture using a technique permitted by the Ethics Committee of Hiroshima University Graduate School of Medicine (Hiroshima, Japan) as described previously (23), and incubated at $37^{\circ} \mathrm{C}$ in a $5 \% \mathrm{CO}_{2}$-humidified atmosphere. The removal of non-adherent cells and detachment of adherent cells from the dishes were performed after $72 \mathrm{~h}$. Adherent cells were then sub-cultured in fresh medium supplemented with $1 \mathrm{ng} / \mathrm{ml}$ fibroblast growth factor-2 every 4-5 days (24). Aliquots of cells were obtained at passages 3-5 and frozen in liquid nitrogen at $-196^{\circ} \mathrm{C}$ for later analyses.

In vitro characterization of human MSCs. MSCs formed adherent monolayers of long, spindle-shaped, fibroblastic cells in the culture medium. MSCs were characterized by Dr Yukihito Higashi (Department of Cardiovascular Physiology and Medicine, Hiroshima University, Hiroshima, Japan) in the past. The method was previously described (23).

Silencing of SPARC expression. To silence SPARC expression, lentiviral particles for short hairpin RNA (sh/shRNA) knockdown (cat. no. sc-37166-V) and control lentiviral particles (cat. no. sc-108080) were purchased from Santa Cruz Biotechnology, Inc. This product was a ready-to-use virus particle (3rd generation packaging system; $200 \mu \mathrm{l}$ viral stock contained $1 \times 10^{6} \mathrm{IFU}$ ). shSPARC and scrambled shRNA lentiviral particles were transfected into KM12SM cells according to the manufacturer's protocols. Cells were cultured in a 12-well plate in medium (DMEM supplemented with $10 \%$ FBS and $1 \%$ penicillin-streptomycin mixture) to $50 \%$ confluence. After $24 \mathrm{~h}$, media were removed and then substituted with $1 \mathrm{ml}$ medium containing polybrene (cat. no. sc-134220; Santa Cruz Biotechnology, Inc.) at a final concentration of $5 \mu \mathrm{g} / \mathrm{ml}$. Cells were infected by adding $20 \mu \mathrm{l}(0.5 \mathrm{MOI})$ of the lentiviral particles to the culture, mixed by swirling and incubated at $37^{\circ} \mathrm{C}$ in a $5 \% \mathrm{CO}_{2}$-humidified atmosphere overnight. At $24 \mathrm{~h}$ post infection, polybrene-containing medium was removed and fresh medium (without polybrene) was added. The cell populations present at $48 \mathrm{~h}$ after infection were then incubated in medium (DMEM supplemented with $10 \%$ FBS and $1 \%$ penicillin-streptomycin mixture) containing the appropriate antibiotic (10 $\mu \mathrm{g} / \mathrm{ml}$ puromycin) for an additional 2 weeks. The cells selected $>2$ weeks after transduction were used for subsequent experimentation. The antibiotic-resistant pools present at each cell passage were then expanded and frozen at $-196^{\circ} \mathrm{C}$.

Reverse transcription-quantitative PCR (RT-qPCR). An RNeasy Kit (Qiagen KK) was used to extract total RNA from KM12SM cells according to the manufacturer's protocol. A first-strand cDNA synthesis kit (Amersham; Cytiva) was used to generate cDNA from $1 \mu \mathrm{g}$ total RNA at $65^{\circ} \mathrm{C}$ for $10 \mathrm{~min}, 0^{\circ} \mathrm{C}$ for $2 \mathrm{~min}$ and $37^{\circ} \mathrm{C}$ for $1 \mathrm{~h}$. After RNA was reverse transcribed into cDNA, RT-qPCR was performed using the LightCycler FastStart DNA Master SYBR-Green I Kit (Roche Diagnostics) according to the manufacturer's protocol. Triplicate reactions were performed. Expression values were reported as $\log 2$ ratios, normalized to $G A P D H$, and subsequently mean-centered to account for differences in the quality and quantity of RNA between samples. The relative expression levels were determined using the $2^{-\triangle \Delta C q}$ method (25). The primer sequences were as follows: SPARC forward, 5'-ATGAGGGCCTGGATCTTCTT-3' and reverse, 5'-CTCTTCGGTTTCCTCTGCAC-3'; and GAPDH forward, 5'-AGAAGGCTGGGGCTCATTTG-3' and reverse, 5'-AGGGGCCATCCACAGTCTTC-3' (SPARC PCR product, $192 \mathrm{bp} ; G A P D H, 258 \mathrm{bp})$. The thermocycling conditions were as follows: Initial denaturation at $94^{\circ} \mathrm{C}$ for $10 \mathrm{~min}$, followed by 30 cycles at $94^{\circ} \mathrm{C}$ for $15 \mathrm{sec}, 58^{\circ} \mathrm{C}$ for $1 \mathrm{~min}$ and $72^{\circ} \mathrm{C}$ for $1.5 \mathrm{~min}$.

In vitro assessment of cell proliferation and motility. KM12SM wild-type (WT) and KM12SM shSPARC (shSPARC) cell lines $\left(6 \times 10^{4}\right.$ cells/well) were seeded into 24 -well plates (ImageLock; Essen Bioscience) containing DMEM supplemented with $0.5 \% \mathrm{FBS}$, and cultured alone or with MSCs ( $6 \times 10^{4}$ cells/well). Bright-field images obtained using a label-free, high-content, time-lapse assay system (IncuCyte ${ }^{\circledR}$ Zoom; Essen Bioscience), which automatically expresses cell confluence over 4 days as a percentage using IncuCyte software (version 2015A Rev1; Essen Bioscience), were used to generate growth curves. These experiments were performed in triplicate.

A scratch wound assay was used to evaluate cell migration. WT or shSPARC cells were seeded at a density of $1 \times 10^{5}$ cells 
per well on $100 \mu \mathrm{g} / \mathrm{ml}$ Matrigel-coated (cat. no. 354234; BD Biosciences; diluted in DMEM supplemented with $0.5 \%$ FBS, coated at $37^{\circ} \mathrm{C}$ for $24 \mathrm{~h}$ ) 96 -well plates (ImageLock; Essen Bioscience) containing DMEM supplemented with 0.5\% FBS either alone or with MSCs ( $1 \times 10^{5}$ cells/well), and the cell monolayer was at or close to $100 \%$ confluence. Wound images were automatically obtained from precise locations on ImageLock 96-well plates using IncuCyte software (version 2015A Rev1; Essen Bioscience) under an inverted microscope having a phase LED lamp and an excitation LED source. The 96-pin wound maker of the IncuCyte system was used to scratch confluent cell layers. After wounding, detached cells were removed by washing with PBS twice, and images were automatically captured every $3 \mathrm{~h}$ for 2 days. IncuCyte software automatically assessed relative wound density. Relative wound density is a measure (\%) of the density of the wound region relative to the density of the cell region and started at $\sim 5 \%$. These experiments were performed in triplicate.

Animals and tumor cell transplantation. Animal experiments were performed as described previously (26). Briefly, a total of 34 female athymic BALB/c nude mice (age, 6 weeks; weight, 14-17 g) were obtained from Charles River Laboratories, Inc. and maintained under specific pathogen-free conditions until 8 weeks of age. The mice were housed in a 12-h light/dark cycle with a humidity of $45-55 \%$ at $22 \pm 1^{\circ} \mathrm{C}$ and had free access to food and water. The methods performed in the present study were approved by the Committee on Animal Experimentation of Hiroshima University (Hiroshima, Japan). Mice were anesthetized via intraperitoneal injection of medetomidine $(0.3 \mathrm{mg} / \mathrm{kg})$, midazolam $(4 \mathrm{mg} / \mathrm{kg})$ and butorfanol $(5 \mathrm{mg} / \mathrm{kg}$ ) (27). In the present study, it was intended to sacrifice mice before significant debilitation due to tumor progression following cancer cell transplantation. Had the tumor been developed earlier than expected and mice were significantly debilitated, the experiment would have been immediately terminated and the mice would have been euthanized. All mice survived during the experiments.

The development of cecal tumors in mice was achieved as follows: WT or shSPARC cells alone $\left(0.5 \times 10^{6}\right)$ or mixed at a ratio of $1: 2$ with MSCs $\left(0.5 \times 10^{6}: 1.0 \times 10^{6} \mathrm{WT}\right.$ cells or shSPARC cells:MSCs) in $50 \mu \mathrm{l} \mathrm{Hanks'} \mathrm{balanced} \mathrm{salt} \mathrm{solution} \mathrm{were}$ implanted by injection into the cecum wall of BALB/c nude mice (age, 8 weeks) under a dissecting microscope according to a previously reported method (9). Mice that survived after 6 weeks (42 days) were then euthanized by cervical dislocation under anesthesia as aforementioned at the end of the experiment, and tumor growth was measured. Tumor tissues were embedded in optimal cutting temperature (OCT) compound, rapidly frozen in liquid nitrogen and stored at $-80^{\circ} \mathrm{C}$.

Necropsy and histological studies. Mice with orthotopic tumors were euthanized under deep anesthesia with a mixture of medetomidine, midazolam and butorphanol, and their body weights were measured. Following necropsy, tumors were excised and weighed. One portion of the tumor was then fixed in formalin-free immunohistochemistry zinc fixative provided as a ready to use solution (BD Pharmingen; BD Biosciences) at room temperature for $24 \mathrm{~h}$ and embedded in paraffin for immunohistochemical analysis, while the remaining portion was embedded in Tissue-Tek OCT compound (Sakura Finetek USA, Inc.), rapidly frozen in liquid nitrogen and stored at $-80^{\circ} \mathrm{C}$. Regional (celiac and para-aortal) lymph nodes that were macroscopically enlarged were harvested, and histological analysis was used to verify tumor metastasis.

Immunohistochemistry. Immunohistochemistry analysis for SPARC, PTX3, FN, FSTL1, LGALS1 and FAP expression in surgical specimens was performed with the tissues, which were fixed with $10 \%$ formalin in PBS at room temperature for at least $48 \mathrm{~h}$, embedded in paraffin, and then cut into serial 4- $\mu$ m-thick sections. Immunohistochemistry analysis for SPARC and Ki-67 expression in transplanted tumors was performed with the tissues, which were fixed in formalin-free immunohistochemistry zinc fixative provided as a ready to use solution (BD Pharmingen; BD Biosciences) at room temperature for $24 \mathrm{~h}$, embedded in paraffin, and then cut into serial 4- $\mu$ m-thick sections. Following deparaffinization in xylene and rehydration in a graded series of ethanol concentrations (from 100 to $70 \%$ ), tissue sections were microwaved twice for $5 \mathrm{~min}$ at $95^{\circ} \mathrm{C}$ in citrate buffer as a pretreatment and then washed three times in PBS for $3 \mathrm{~min}$ at room temperature. Endogenous peroxidase activity was blocked by incubation with $3 \%$ hydrogen peroxide in methanol for $10 \mathrm{~min}$ at room temperature. The tissue sections were then washed three times with PBS and blocked with protein blocking solution [5\% normal horse serum (cat. no. H1138; Sigma-Aldrich; Merck KGaA) and 1\% normal goat serum (cat. no. G6767; Sigma-Aldrich; Merck KGaA) in PBS] at room temperature for $10 \mathrm{~min}$. After washing three time in PBS, primary antibodies (SPARC dilution, 1:100; PTX3 dilution, 1:500; FN dilution, 1:200; FSTL1 dilution, 1:200; LGALS1 dilution, 1:100; FAP dilution, 1:100; Ki-67 dilution, 1:1,000) were added to the slides, which were then incubated in humidified boxes at $4^{\circ} \mathrm{C}$ overnight. The slides were then washed three times in PBS. Following a further incubation at room temperature for $1 \mathrm{~h}$ with the respective peroxidase-conjugated secondary antibodies (dilution, 1:500), a positive reaction was detected by exposing slides to stable 3,3'-diaminobenzidine at room temperature for 5-10 min. To visualize nuclei, slides were then counterstained with hematoxylin (cat. no. 1.09249.0500; Merck $\mathrm{KGaA}$ ) used as undiluted solution at room temperature for $15 \mathrm{sec}$. SPARC, PTX3, FN, FSTL1 and LGALS1 staining was defined as positive when $\geq 30 \%$ of cancer cells were stained as previously described (28-31). The areas of FAP-positive staining and SPARC-positive staining were measured in five optical fields (magnification, x100) from different sections by light microscopy and calculated using ImageJ software (version 1.51j8; National Institutes of Health).

Immunofluorescence staining. Frozen specimens were cut into $8-\mu \mathrm{m}$-thick sections, and cells cultured on glass slides were fixed for $15 \mathrm{~min}$ in $4 \%$ paraformaldehyde in PBS at room temperature. Slides were briefly blocked with protein blocking solution [5\% normal horse serum (cat. no. H1138; Sigma-Aldrich; Merck KGaA) and $1 \%$ normal goat serum (cat. no. G6767; Sigma-Aldrich; Merck KGaA) in PBS] at room temperature for $10 \mathrm{~min}$, incubated at $4^{\circ} \mathrm{C}$ overnight with the Fab fragment of anti-mouse IgG (dilution, 1:500; cat. no. 115-067-003; Jackson ImmunoResearch Laboratories, 
Inc.) to block endogenous immunoglobulins if necessary, and incubated at $4^{\circ} \mathrm{C}$ overnight with anti-CD31 (dilution, 1:50), anti-Lyve1 (dilution, 1:20), anti- $\alpha$-SMA (dilution, 1:200) or anti-type I collagen (dilution, 1:500). Slides were washed with PBS and incubated with the Alexa Fluor 546 or 568-labeled secondary antibody (dilution, 1:500) at room temperature for $1 \mathrm{~h}$. A nuclear counterstain with DAPI (1:500) was applied at room temperature for $10 \mathrm{~min}$, and the mounting medium (Fluoromount/Plus; cat. no. K048; Diagnostic BioSystems) was placed on each specimen with a glass coverslip. The all-in-one fluorescence microscope BZ-X710 (Keyence Corporation) with a $20 \mathrm{X}$ or $40 \mathrm{X}$ objective lens was used to capture confocal fluorescence images.

Double immunofluorescence staining of FN and E-cadherin. To identify EMT, immunofluorescence staining was conducted as described in the previous section using the slides of frozen specimens, cut into $8-\mu \mathrm{m}$-thick sections. Endogenous peroxidase activity was blocked by incubation with $3 \%$ hydrogen peroxide in methanol for $10 \mathrm{~min}$ at room temperature. The tissue sections were then washed three times with PBS. Slides were briefly blocked with protein blocking solution [5\% normal horse serum (cat. no. H1138; Sigma-Aldrich; Merck KGaA) and 1\% normal goat serum (cat. no. G6767; Sigma-Aldrich; Merck KGaA) in PBS] at room temperature for $10 \mathrm{~min}$. After washing three time in PBS, slides were incubated with the anti-FN antibody (dilution, $1: 100$ ) at $4^{\circ} \mathrm{C}$ overnight, followed by the Alexa 568-conjugated donkey anti-goat IgG secondary antibody (dilution, 1:500) at room temperature for $1 \mathrm{~h}$. Slides were then placed in a blocking solution as aforementioned and incubated with the antibody against E-cadherin (dilution, $1: 100$ ) at $4^{\circ} \mathrm{C}$ overnight. Following washing with PBS and blocking with blocking solution [5\% normal horse serum (cat. no. H1138; Sigma-Aldrich; Merck KGaA) and 1\% normal goat serum (cat. no. G6767; Sigma-Aldrich; Merck KGaA) in PBS] at room temperature for $10 \mathrm{~min}$ as aforementioned, slides were incubated with the Alexa 488-conjugated goat anti-rabbit IgG secondary antibody (dilution, 1:500) at room temperature for $1 \mathrm{~h}$. FN (a mesenchymal marker) was identified by red fluorescence and E-cadherin (an epithelial marker) was identified by green fluorescence. The all-in-one fluorescence microscope BZ-X710 (Keyence Corporation) was used to capture confocal fluorescence images.

Quantification of microvessels, lymphatic vessels, CAF and collagen areas. Using specimens stained as aforementioned, assessments of the angiogenic and lymphangiogenic activities of tumors were conducted based on quantifying the respective areas in vascular and lymphatic microvessels. The microvessel (CD31-positive staining) and lymphatic vessel (Lyve-1-positive staining) areas were measured in five optical fields (magnification, x100) from different sections and calculated using ImageJ software (version 1.51j8; National Institutes of Health). CAF and ECM areas were also evaluated in the respective areas of $\alpha$-SMA-positive or type-1 collagen-positive staining in five optical fields (magnification, $\mathrm{x} 100)$ from different sections.

Ki-67 labeling index (Ki-67 LI). Using specimens stained as aforementioned, the $\mathrm{Ki}-67 \mathrm{LI}$ was evaluated at the site with the highest number of Ki-67-positive cells under a light microscope. The cells were counted in ten fields (magnification, $\mathrm{x} 40$ ), and the number of positive cells among $\sim 1,000$ tumor cells was expressed as a percentage.

RNA sequencing. Tumors formed by co-transplantation of WT and MSCs (WT + MSCs) or shSPARC and MSCs (shSPARC + MSCs) were mechanically disassociated using a homogenizer. Subsequently, an RNeasy Mini kit (cat. no. 74104; Qiagen $\mathrm{GmbH}$ ) was used for RNA extraction according to the manufacturer's protocols. Library construction and data processing were performed by Beijing Genomics Institute (Beijing, China). Concentration was measured using ExKubit dsDNA HS Assay Kits (cat. no. NGS00-3012; Shanghai ExCell Biology, Inc.) and Fluostar Omega Microplate Reader (BMG Labtech GmbH). Fragment size was detected using a DNA 1000 Kit (part no. 5067-1504; Agilent Technologies, Inc.) and 2100 Bioanalyzer Instrument (Agilent Technologies, Inc.). Libraries were sequenced on a DNBSEQ-G400RS platform, and high-quality reads were aligned to the human reference genome (GRCh38). The sequencing kit was DNBSEQ-G400RS High-throughput Sequencing Set (FCL PE100) (cat. no. 1000016950; MGI Tech Co., Ltd.) and paired-end sequencing $(2 \times 100 \mathrm{bp})$ was performed. Concentration was measured using a Qubit ${ }^{\mathrm{TM}}$ ssDNA Assay Kit (cat. no. Q10212; Invitrogen; Thermo Fisher Scientific, Inc.) and Qubit 4 Fluorometer (Invitrogen; Thermo Fisher Scientific, Inc.). The loading concentration was 8-20 ng/ $\mu \mathrm{l}$. The genome reference was GCF_000001405.38_GRCh38. p12. The software used to analyze the data was as follows: Filter: SOAPnuke-1.5.6, Alignment hisat: Hisat2-2.1.0 (32), Alignment bowtie: Bowtie2-2.3.4.3 (33), Expression RSEM: rsem_calculate_expression rsem-1.2.28-0 (34), SNP INDEL: GenomeAnalysisTK (35), Structure Fusion ericscript: Ericscript, Structure AS rMATS: rMATS.3.2.5 (36). Gene Ontology (GO; geneontology.org) and Kyoto Encyclopedia of Genes and Genomes (KEGG; https://www.genome.jp/kegg/) pathway analyses were performed using the RNA Data Visualization System Dr. TOM (Beijing Genomics Institute; https://www.bgi.com/global/dr-tom/), a BGI in-house customized data mining system which combines different published software. Gene set enrichment analysis (GSEA) was performed as previously described (37) to analyze the differential modulation of molecular pathways in the all canonical pathway gene set (C2.CP) from the v7.0 MSigDB gene set collection (https:/www.gsea-msigdb.org/gsea/msigdb/).

Statistical analysis. Statistical analyses were performed using JMP statistical software version 15.0.0. (SAS Institute, Inc.). Significant differences between the WT and shSPARC groups in the in vitro and in vivo experiments were assessed using the Mann-Whitney U test. The Fisher's exact test was used to investigate the association between the proteins tested (SPARC, PTX3, FN, FSTL1 and LGALS1) and each patient's clinicopathological characteristics. Univariate analysis was conducted using Cox proportional-hazards model. Kaplan-Meier curves were created to examine survival rates, and the log-rank test was used to statistically compare the Kaplan-Meier curves. Data are presented as the mean \pm SEM. Experiments were repeated three times independently. $\mathrm{P}<0.05$ was considered to indicate a statistically significant difference. 


\section{Results}

SPARC expression in cancer cells of human CRC is an effective prognostic marker. Immunostaining for SPARC, PTX3, FN, FSTL1 and LGALS1 was performed in 42 resected human CRC specimens (Fig. 1A). SPARC was evaluated for staining in cancer cells and stroma, respectively, and the others were evaluated for staining in cancer cells. High $\mathrm{T}$ grade $(\mathrm{P}<0.01), \mathrm{N}$ grade $(\mathrm{P}<0.05)$ and stage $(\mathrm{P}<0.01)$ were significantly more frequent in cancer cells expressing SPARC compared with those that did not (Table I). Kaplan-Meier survival curve analysis revealed significantly poorer prognoses in cases expressing SPARC in tumors compared with those that did not $(\mathrm{P}<0.01$; Fig. 1B). Furthermore, univariate Cox proportional-hazards analysis demonstrated that the prognosis was significantly poorer in CRC cases with positive SPARC expression (Table II). These results indicated that SPARC expression in CRC cells may be a useful prognostic biomarker.

Additionally, a significant difference was observed in the $M$ grade based on LGALS1 expression $(\mathrm{P}<0.05$; Table III), while no significant association was observed between FSTL1 (Table IV), FN (Table V) and PTX3 (Table VI) expression and clinicopathological factors. However, the prognosis was significantly worse in cases with FN expression compared with those without $(\mathrm{P}<0.05$; Fig. $1 \mathrm{G})$, while no significant associations were observed for the remaining proteins (Fig. 1D-F).

Since it has been reported that SPARC expression in the stroma of CRC is associated with prognosis (38), the present study also investigated SPARC expression in the stroma and found no association with prognosis or any of the examined clinicopathological factors (Fig. 1C; Table VII).

In addition, to verify whether SPARC expression is induced by the interaction between cancer cells and activated stroma, immunostaining for FAP (Fig. S1A), a CAF marker, was conducted to determine whether an association exists between the CAF volume around cancer cells and cancer cell SPARC expression. The results demonstrated that the FAP-positive area was significantly larger in SPARC-expressing cases compared with negative cases (Fig. S1B), suggesting that the interaction between cancer cells and CAFs induces SPARC expression, which may affect tumor progression and patient prognosis.

In vitro migration and proliferation are suppressed in co-cultures of the KM12SM shSPARC cell line and MSCs. A KM12SM cell line with silenced SPARC expression was generated using a SPARC shRNA lentiviral vector (shSPARC). KM12SM WT (WT) and shSPARC cells were labeled with GFP and co-cultured with MSCs. To remove MSCs, flow cytometry was performed as previously described (12). SPARC expression in each cell line was quantified using PCR. shSPARC cells were demonstrated to exhibit reduced SPARC expression (Fig. 2A). To compare proliferation and migration abilities, WT and shSPARC cells were cultured either alone or with MSCs. No significant differences were observed between the proliferation capacity of WT and shSPARC cells when cultured alone (Fig. 2B). However, the proliferation ability of shSPARC cells was significantly suppressed in co-culture with MSCs compared with that of WT cells co-cultured with MSCs $(\mathrm{P}<0.05$;
Table I. Association between SPARC expression in tumor cells and clinicopathological characteristics.

\begin{tabular}{|c|c|c|c|}
\hline \multirow[b]{2}{*}{ Characteristics } & \multicolumn{2}{|c|}{ SPARC expression } & \multirow[b]{2}{*}{ P-value } \\
\hline & Positive, n (\%) & Negative, n (\%) & \\
\hline \multicolumn{4}{|l|}{ Age, years } \\
\hline$\geq 65(n=33)$ & $20(61)$ & $13(39)$ & $>0.99$ \\
\hline$<65(\mathrm{n}=9)$ & $6(67)$ & $3(33)$ & \\
\hline \multicolumn{4}{|l|}{ Sex } \\
\hline Male $(n=23)$ & $14(61)$ & $9(39)$ & $>0.99$ \\
\hline Female $(\mathrm{n}=19)$ & $12(63)$ & 7 (37) & \\
\hline \multicolumn{4}{|l|}{$\mathrm{T}$ classification } \\
\hline $\mathrm{T} 1(\mathrm{n}=7)$ & $0(0)$ & $7(100)$ & $<0.01$ \\
\hline $\mathrm{T} 2 / 3 / 4(\mathrm{n}=35)$ & $26(74)$ & $9(26)$ & \\
\hline \multicolumn{4}{|l|}{$\mathrm{N}$ classification } \\
\hline N0 $(n=20)$ & $8(40)$ & $12(60)$ & $<0.05$ \\
\hline $\mathrm{N} 1 / 2 / 3(\mathrm{n}=22)$ & $18(82)$ & $4(18)$ & \\
\hline \multicolumn{4}{|l|}{ M classification } \\
\hline M0 (n=37) & $21(57)$ & $16(43)$ & 0.14 \\
\hline M1 (n=5) & $5(100)$ & $0(0)$ & \\
\hline \multicolumn{4}{|l|}{ Stage } \\
\hline $\mathrm{I} / \mathrm{II}(\mathrm{n}=18)$ & $6(33)$ & $12(67)$ & $<0.01$ \\
\hline III/IV (n=24) & $20(83)$ & $4(17)$ & \\
\hline \multicolumn{4}{|l|}{ Lymphatic invasion } \\
\hline ly0 (n=29) & $17(59)$ & $12(41)$ & 0.73 \\
\hline ly $1 / 2 / 3(n=13)$ & $9(69)$ & $4(31)$ & \\
\hline \multicolumn{4}{|l|}{ Vessel invasion } \\
\hline v0 (n=28) & $15(54)$ & $13(46)$ & 0.18 \\
\hline$v 1 / 2 / 3(n=14)$ & $11(79)$ & $3(21)$ & \\
\hline \multicolumn{4}{|l|}{ Histological type } \\
\hline Well (n=38) & $23(61)$ & $15(39)$ & 1 \\
\hline Moderately $(n=4)$ & $3(75)$ & $1(25)$ & \\
\hline
\end{tabular}

SPARC, secreted protein acidic and rich in cysteine; ly, lymphatic involvement; $\mathrm{v}$, venous involvement.

Fig. 2C). Furthermore, no significant difference in the migration ability was observed when the cells were cultured alone (Fig. 2D, F and G). However, migration was significantly inhibited in shSPARC cells following co-culture with MSCs compared with WT cells co-cultured with MSCs (Fig. 2E, H and I; $\mathrm{P}<0.05$ ). These results indicated that $S P A R C$ expression in cancer cells promoted cell proliferation and migration. Furthermore, direct contact between cancer cells and MSCs was essential for these SPARC functions.

Growth and metastasis of KM12SM shSPARC orthotopic tumors co-transplanted with MSCs are significantly suppressed. Orthotopically transplanted tumors were generated to investigate how SPARC expression in CRC cells affected tumor growth and development. First, tumors transplanted with WT and shSPARC alone were generated and compared with each other (Table VIII; Fig. S2A and B). 
Table II. Univariate Cox regression analyses of SPARC expression.

\begin{tabular}{|c|c|c|}
\hline \multirow[b]{2}{*}{ Variable } & \multicolumn{2}{|c|}{ Univariate analysis } \\
\hline & $\mathrm{HR}(95 \% \mathrm{CI})$ & P-value \\
\hline Age, years & & 0.46 \\
\hline$<65$ & 1 (Ref.) & \\
\hline$\geq 65$ & $1.719(0.448-11.241)$ & \\
\hline Stage & & 0.06 \\
\hline $\mathrm{I} / \mathrm{II}$ & 1 (Ref.) & \\
\hline III/IV & $3.640(0.958-23.702)$ & \\
\hline Histological type & & 0.12 \\
\hline tub1 & 1 (Ref.) & \\
\hline tub2 & $3.212(0.706-10.928)$ & \\
\hline SPARC & & $<0.01$ \\
\hline Negative & 1 (Ref.) & \\
\hline Positive & $9.792(1.895-179.207)$ & \\
\hline
\end{tabular}

HR, hazard ratio; CI, confidence interval; SPARC, secreted protein acidic and rich in cysteine; tub1, well differentiated tubular adenocarcinoma; tub2, moderately differentiated tubular adenocarcinoma.

Since the in vitro experiments revealed that direct contact with MSCs was required for SPARC function in cancer cells, tumors co-transplanted with WT + MSCs and shSPARC + MSCs were generated (Table VIII; Fig. S2C and D). A tendency for reduced body weight loss and tumor weight was observed in mice transplanted with only shSPARC tumors compared with WT tumors; however, these differences were not statistically significant (Table VIII; Fig. S2A and B). By contrast, co-transplantation of shSPARC + MSCs induced a significant reduction in body weight loss, tumor weight and lymph node metastasis rate compared with the group co-transplanted with WT + MSCs $(\mathrm{P}<0.05$; Table VIII; Fig. S2C and D). These results indicated that SPARC was associated with the promotion of tumor growth and metastasis, and its function was more pronounced following co-transplantation with MSCs.

Angiogenesis and EMT are significantly downregulated in KM12SM shSPARC orthotopic tumors co-transplanted with MSCs. All orthotopically transplanted tumors were immunohistologically compared. In mice transplanted with WT or shSPARC alone, hematoxylin and eosin staining revealed that WT tumors developed invasively with stromal reaction, whereas shSPARC tumors developed expansively. A similar trend was observed in tumors co-transplanted with MSCs, although the stromal reaction was more pronounced in tumors co-transplanted with WT + MSCs than in tumors transplanted with WT alone (Fig. 3A).

Immunostaining further demonstrated that SPARC was positively expressed in WT and WT + MSCs tumors and downregulated in shSPARC and shSPARC + MSCs tumors (Fig. 3B). Furthermore, the Ki-67 LI was significantly reduced in shSPARC + MSCs tumors compared with WT + MSCs
Table III. Association between LGALS1 expression in tumor cells and clinicopathological characteristics.

\begin{tabular}{|c|c|c|c|}
\hline \multirow[b]{2}{*}{ Characteristics } & \multicolumn{2}{|c|}{ LGALS1 expression } & \multirow[b]{2}{*}{ P-value } \\
\hline & Positive, n (\%) & Negative, n (\%) & \\
\hline \multicolumn{4}{|l|}{ Age, years } \\
\hline$\geq 65(n=33)$ & $12(36)$ & $21(64)$ & $>0.99$ \\
\hline$<65(\mathrm{n}=9)$ & $3(33)$ & $6(67)$ & \\
\hline \multicolumn{4}{|l|}{ Sex } \\
\hline Male (n=23) & $8(35)$ & $15(65)$ & $>0.99$ \\
\hline Female $(\mathrm{n}=19)$ & $7(37)$ & $12(63)$ & \\
\hline \multicolumn{4}{|l|}{$\mathrm{T}$ classification } \\
\hline $\mathrm{T} 1(\mathrm{n}=7)$ & $4(57)$ & $3(43)$ & 0.23 \\
\hline $\mathrm{T} 2 / 3 / 4(\mathrm{n}=35)$ & $11(31)$ & $24(69)$ & \\
\hline \multicolumn{4}{|l|}{$\mathrm{N}$ classification } \\
\hline NO $(n=20)$ & $7(35)$ & $13(65)$ & $>0.99$ \\
\hline $\mathrm{N} 1 / 2 / 3(\mathrm{n}=22)$ & $8(36)$ & $14(64)$ & \\
\hline \multicolumn{4}{|l|}{ M classification } \\
\hline M0 (n=37) & $11(30)$ & $26(70)$ & $<0.05$ \\
\hline M1 $(n=5)$ & $4(80)$ & $1(20)$ & \\
\hline \multicolumn{4}{|l|}{ Stage } \\
\hline $\mathrm{I} / \mathrm{II}(\mathrm{n}=18)$ & $6(33)$ & $12(67)$ & $>0.99$ \\
\hline III/IV (n=24) & $9(38)$ & $15(62)$ & \\
\hline \multicolumn{4}{|l|}{ Lymphatic invasion } \\
\hline ly0 (n=29) & $9(31)$ & $20(69)$ & 0.49 \\
\hline ly $1 / 2 / 3(n=13)$ & $6(46)$ & $7(54)$ & \\
\hline \multicolumn{4}{|l|}{ Vessel invasion } \\
\hline v0 $(n=28)$ & $12(43)$ & $16(57)$ & 0.31 \\
\hline $\mathrm{v} 1 / 2 / 3(\mathrm{n}=14)$ & $3(21)$ & $11(79)$ & \\
\hline \multicolumn{4}{|l|}{ Histological type } \\
\hline Well $(\mathrm{n}=38)$ & $12(32)$ & $26(68)$ & 0.12 \\
\hline Moderately $(n=4)$ & $3(75)$ & $1(25)$ & \\
\hline
\end{tabular}

LGALS1, galectin-1; ly, lymphatic involvement; v, venous involvement.

tumors, although no significant difference was observed for single transplant tumors (Fig. 3C).

The areas of CD31- and Lyve1-positive immunostaining were quantified to evaluate vessel area (Fig. 3D and E). Additionally, the positive immunostaining areas for $\alpha$-SMA and type I collagen were quantified to analyze stromal area (Fig. 3F and G). The positive CD31 and Lyve1 areas did not differ between WT and shSPARC tumors. However, their positive areas were significantly reduced in shSPARC + MSCs tumors compared with WT + MSCs tumors $(\mathrm{P}<0.01$; Fig. 3D and E). Furthermore, the positive areas for $\alpha$-SMA and type I collagen were significantly reduced in shSPARC tumors for both single transplanted tumors and MSCs co-transplanted tumors.

Furthermore, double immunostaining was performed using the epithelial marker E-cadherin and the stromal marker FN to assess EMT in co-transplanted tumors. Both E-cadherin 
Table IV. Association between FSTL1 expression in tumor cells and clinicopathological characteristics.

\begin{tabular}{|c|c|c|c|}
\hline \multirow[b]{2}{*}{ Characteristics } & \multicolumn{2}{|c|}{ FSTL1 expression } & \multirow[b]{2}{*}{ P-value } \\
\hline & Positive, n (\%) & Negative, n (\%) & \\
\hline \multicolumn{4}{|l|}{ Age, years } \\
\hline$\geq 65(n=33)$ & $13(39)$ & $20(61)$ & 0.23 \\
\hline$<65(\mathrm{n}=9)$ & $1(11)$ & $8(89)$ & \\
\hline \multicolumn{4}{|l|}{ Sex } \\
\hline Male $(n=23)$ & $9(39)$ & $14(61)$ & 0.51 \\
\hline Female $(n=19)$ & $5(26)$ & $14(74)$ & \\
\hline \multicolumn{4}{|l|}{$\mathrm{T}$ classification } \\
\hline $\mathrm{T} 1(\mathrm{n}=7)$ & $0(0)$ & $7(100)$ & 0.08 \\
\hline $\mathrm{T} 2 / 3 / 4(\mathrm{n}=35)$ & $14(40)$ & $21(60)$ & \\
\hline \multicolumn{4}{|l|}{$\mathrm{N}$ classification } \\
\hline N0 $(n=20)$ & $5(25)$ & $15(75)$ & 0.34 \\
\hline $\mathrm{N} 1 / 2 / 3(\mathrm{n}=22)$ & $9(41)$ & $13(59)$ & \\
\hline \multicolumn{4}{|l|}{ M classification } \\
\hline M0 (n=37) & $12(32)$ & $25(68)$ & $>0.99$ \\
\hline M1 (n=5) & $2(40)$ & $3(60)$ & \\
\hline \multicolumn{4}{|l|}{ Stage } \\
\hline $\mathrm{I} / \mathrm{II}(\mathrm{n}=18)$ & $4(22)$ & $14(78)$ & 0.32 \\
\hline III/IV (n=24) & $10(42)$ & $14(58)$ & \\
\hline \multicolumn{4}{|l|}{ Lymphatic invasion } \\
\hline ly0 (n=29) & $8(28)$ & $21(72)$ & 0.30 \\
\hline ly $1 / 2 / 3(n=13)$ & $6(46)$ & $7(54)$ & \\
\hline \multicolumn{4}{|l|}{ Vessel invasion } \\
\hline v0 (n=28) & $9(32)$ & $19(68)$ & $>0.99$ \\
\hline $\mathrm{v} 1 / 2 / 3(\mathrm{n}=14)$ & $5(36)$ & $9(64)$ & \\
\hline \multicolumn{4}{|l|}{ Histological type } \\
\hline Well $(n=38)$ & $12(32)$ & $26(68)$ & 0.59 \\
\hline Moderately $(n=4)$ & $2(50)$ & $2(50)$ & \\
\hline
\end{tabular}

FSTL1, follistatin-related protein 1; ly, lymphatic involvement; $\mathrm{v}$, venous involvement.

and FN were expressed at the edge of cancer cell nests in WT + MSCs tumors, whereas no such changes were observed at the edge of cancer nests in shSPARC + MSCs tumors, which only expressed E-cadherin (Fig. $3 \mathrm{H})$. This result suggested that SPARC-mediated EMT occurred at the edge of the cancer cell nest where cancer cells and stromal cells are in direct contact with each other.

SPARC positively regulates signaling pathways and gene sets associated with stromal reactions, angiogenesis and $E M T$. To investigate the effect of SPARC on gene expression in transplanted tumors, mRNAs from WT + MSCs and shSPARC + MSCs tumors were analyzed. Subsequently, GO biological process enrichment analysis, KEGG pathway enrichment analysis and GSEA were performed to evaluate gene expression and pathway differences. Since the in vitro and in vivo experimental results demonstrated that SPARC
Table V. Association between FN expression in tumor cells and clinicopathological characteristics.

\begin{tabular}{|c|c|c|c|}
\hline \multirow[b]{2}{*}{ Characteristics } & \multicolumn{2}{|c|}{ FN expression } & \multirow[b]{2}{*}{ P-value } \\
\hline & Positive, n (\%) & Negative, n (\%) & \\
\hline \multicolumn{4}{|l|}{ Age, years } \\
\hline$\geq 65(n=33)$ & $12(33)$ & $21(67)$ & 0.69 \\
\hline$<65(\mathrm{n}=9)$ & $2(22)$ & $7(78)$ & \\
\hline \multicolumn{4}{|l|}{ Sex } \\
\hline Male $(n=23)$ & $7(30)$ & $16(70)$ & 0.75 \\
\hline Female $(\mathrm{n}=19)$ & $7(32)$ & $12(68)$ & \\
\hline \multicolumn{4}{|l|}{ T classification } \\
\hline $\mathrm{T} 1(\mathrm{n}=7)$ & $2(29)$ & $5(71)$ & $>0.99$ \\
\hline $\mathrm{T} 2 / 3 / 4(\mathrm{n}=35)$ & $12(31)$ & $23(69)$ & \\
\hline \multicolumn{4}{|l|}{$\mathrm{N}$ classification } \\
\hline NO $(n=20)$ & $6(25)$ & $14(75)$ & 0.75 \\
\hline $\mathrm{N} 1 / 2 / 3(\mathrm{n}=22)$ & $8(36)$ & $14(64)$ & \\
\hline \multicolumn{4}{|l|}{ M classification } \\
\hline M0 (n=37) & $12(30)$ & $25(70)$ & $>0.99$ \\
\hline M1 (n=5) & $2(40)$ & $3(60)$ & \\
\hline \multicolumn{4}{|l|}{ Stage } \\
\hline $\mathrm{I} / \mathrm{II}(\mathrm{n}=18)$ & $4(17)$ & $14(83)$ & 0.32 \\
\hline III/IV (n=24) & $10(42)$ & $14(58)$ & \\
\hline \multicolumn{4}{|l|}{ Lymphatic invasion } \\
\hline ly0 (n=29) & $9(28)$ & $20(72)$ & 0.73 \\
\hline ly $1 / 2 / 3(n=13)$ & $5(38)$ & $8(62)$ & \\
\hline \multicolumn{4}{|l|}{ Vessel invasion } \\
\hline v0 $(n=28)$ & $11(36)$ & $17(64)$ & 0.31 \\
\hline $\mathrm{v} 1 / 2 / 3(\mathrm{n}=14)$ & $3(21)$ & $11(79)$ & \\
\hline \multicolumn{4}{|l|}{ Histological type } \\
\hline Well $(n=38)$ & $12(29)$ & $26(71)$ & 0.59 \\
\hline Moderately $(n=4)$ & $2(50)$ & $2(50)$ & \\
\hline
\end{tabular}

FN, fibronectin; ly, lymphatic involvement; v, venous involvement.

was associated with cell proliferation, migration, angiogenesis and EMT, factors related to these processes were extracted from the top rankings with q-value $<0.25$.

In GO analysis, WT + MSCs tumors exhibited significantly increased expression levels of genes associated with 'cell migration', 'cell proliferation', 'angiogenesis', 'positive regulation of extracellular matrix assembly' and 'positive regulation of epithelial to mesenchymal transition' compared with shSPARC + MSCs tumors (Fig. 4A).

KEGG pathway analysis revealed significant activation of 'axon guidance', 'MAPK signaling pathway', 'TGF- $\beta$ signaling pathway' and 'p53 signaling pathway' in WT + MSCs tumors (Fig. 4B).

GSEA revealed a significant increase in gene set expression related to stromal reaction, angiogenesis, EMT and cell proliferation in WT + MSCs tumors (Fig. 4C). Among them, the increased expression of gene sets related to stromal formation was predominant. 
Table VI. Association between PTX3 expression in tumor cells and clinicopathological characteristics.

\begin{tabular}{|c|c|c|c|}
\hline \multirow[b]{2}{*}{ Characteristics } & \multicolumn{2}{|c|}{ PTX3 expression } & \multirow[b]{2}{*}{ P-value } \\
\hline & Positive, n (\%) & Negative, n (\%) & \\
\hline \multicolumn{4}{|l|}{ Age, years } \\
\hline$\geq 65(n=33)$ & $15(45)$ & $18(55)$ & 0.27 \\
\hline$<65(\mathrm{n}=9)$ & $2(22)$ & $7(78)$ & \\
\hline \multicolumn{4}{|l|}{ Sex } \\
\hline Male $(n=23)$ & $8(35)$ & $15(65)$ & 0.53 \\
\hline Female $(\mathrm{n}=19)$ & $9(47)$ & $10(53)$ & \\
\hline \multicolumn{4}{|l|}{$\mathrm{T}$ classification } \\
\hline $\mathrm{T} 1(\mathrm{n}=7)$ & $2(29)$ & $5(71)$ & 0.68 \\
\hline $\mathrm{T} 2 / 3 / 4(\mathrm{n}=35)$ & $15(43)$ & $20(57)$ & \\
\hline \multicolumn{4}{|l|}{$\mathrm{N}$ classification } \\
\hline N0 $(n=20)$ & $9(45)$ & $11(55)$ & 0.75 \\
\hline $\mathrm{N} 1 / 2 / 3(\mathrm{n}=22)$ & $8(36)$ & $14(64)$ & \\
\hline \multicolumn{4}{|l|}{ M classification } \\
\hline M0 (n=37) & $14(38)$ & $23(62)$ & 0.38 \\
\hline M1 $(n=5)$ & $3(60)$ & $2(40)$ & \\
\hline \multicolumn{4}{|l|}{ Stage } \\
\hline $\mathrm{I} / \mathrm{II}(\mathrm{n}=18)$ & $8(44)$ & $10(56)$ & 0.75 \\
\hline III/IV (n=24) & $9(38)$ & $15(62)$ & \\
\hline \multicolumn{4}{|l|}{ Lymphatic invasion } \\
\hline ly0 (n=29) & $12(41)$ & $17(59)$ & $>0.99$ \\
\hline ly $1 / 2 / 3(n=13)$ & $5(38)$ & $8(62)$ & \\
\hline \multicolumn{4}{|l|}{ Vessel invasion } \\
\hline v0 (n=28) & $12(43)$ & $16(57)$ & 0.75 \\
\hline $\mathrm{v} 1 / 2 / 3(\mathrm{n}=14)$ & $5(36)$ & $9(64)$ & \\
\hline \multicolumn{4}{|l|}{ Histological type } \\
\hline Well $(n=38)$ & $14(37)$ & $24(63)$ & 0.29 \\
\hline Moderately $(n=4)$ & $3(75)$ & $1(25)$ & \\
\hline
\end{tabular}

PTX3, pentraxin 3; ly, lymphatic involvement; v, venous involvement.

These results suggest the importance of SPARC expression in the process of tumor microenvironment formation via cancer-stromal interactions. Additionally, RNA sequencing also revealed that the expression levels of genes and signaling pathways associated with stromal reactions, angiogenesis and EMT were suppressed in tumors co-transplanted with shSPARC and MSCs, and these mRNA sequencing results were consistent with the immunohistology findings; co-transplantation of MSCs and shSPARC tumors suppressed growth, stromal reactions and EMT compared with co-transplantation of MSCs and WT tumors.

\section{Discussion}

The incidence of CRC and its associated mortality rate remain high, with distant metastasis and tumor recurrence negatively affecting patient prognoses. Therefore, the identification of effective markers for detecting CRC development or metastasis
Table VII. Association between SPARC expression in stromal cells and clinicopathological characteristics.

\begin{tabular}{|c|c|c|c|}
\hline \multirow[b]{2}{*}{ Characteristics } & \multicolumn{2}{|c|}{ SPARC expression } & \multirow[b]{2}{*}{ P-value } \\
\hline & Positive, n (\%) & Negative, n (\%) & \\
\hline \multicolumn{4}{|l|}{ Age, years } \\
\hline$\geq 65(n=33)$ & $23(70)$ & $10(30)$ & 0.40 \\
\hline$<65(\mathrm{n}=9)$ & $8(89)$ & $1(11)$ & \\
\hline \multicolumn{4}{|l|}{ Sex } \\
\hline Male $(n=23)$ & $17(74)$ & $6(26)$ & $>0.99$ \\
\hline Female $(n=19)$ & $14(74)$ & $5(26)$ & \\
\hline \multicolumn{4}{|l|}{$\mathrm{T}$ classification } \\
\hline $\mathrm{T} 1(\mathrm{n}=7)$ & $6(86)$ & $1(14)$ & 0.65 \\
\hline $\mathrm{T} 2 / 3 / 4(\mathrm{n}=35)$ & $25(71)$ & $10(29)$ & \\
\hline \multicolumn{4}{|l|}{$\mathrm{N}$ classification } \\
\hline N0 $(n=20)$ & $17(85)$ & $3(15)$ & 0.17 \\
\hline$N 1 / 2 / 3(n=22)$ & $14(64)$ & $8(36)$ & \\
\hline \multicolumn{4}{|l|}{ M classification } \\
\hline M0 (n=37) & $28(76)$ & $9(26)$ & 0.59 \\
\hline M1 $(n=5)$ & $3(60)$ & $2(40)$ & \\
\hline \multicolumn{4}{|l|}{ Stage } \\
\hline $\mathrm{I} / \mathrm{II}(\mathrm{n}=18)$ & $15(83)$ & $3(17)$ & 0.30 \\
\hline III/IV (n=24) & $16(67)$ & $8(33)$ & \\
\hline \multicolumn{4}{|l|}{ Lymphatic invasion } \\
\hline ly0 (n=29) & $24(83)$ & $5(17)$ & 0.07 \\
\hline ly $1 / 2 / 3(n=13)$ & $7(54)$ & $6(46)$ & \\
\hline \multicolumn{4}{|l|}{ Vessel invasion } \\
\hline v0 (n=28) & $23(82)$ & $5(18)$ & 0.14 \\
\hline $\mathrm{v} 1 / 2 / 3(\mathrm{n}=14)$ & $8(57)$ & $6(43)$ & \\
\hline \multicolumn{4}{|l|}{ Histological type } \\
\hline Well $(n=38)$ & $28(74)$ & $10(26)$ & 1 \\
\hline Moderately (n=4) & $3(75)$ & $1(25)$ & \\
\hline
\end{tabular}

SPARC, secreted protein acidic and rich in cysteine; ly, lymphatic involvement; $v$, venous involvement.

is essential for designing effective preventative and therapeutic strategies for CRC.

To clarify the mechanism by which MSCs promote tumor progression, microarray analysis was performed in our previous study (12) and gene expression changes in cancer cells induced following co-culture with MSCs were comprehensively evaluated. Direct co-culture with MSCs induced EMT-related genes, such as SPARC, FN1, LGALS, FSTL1 and $P T X 3$, in KM12SM cancer cells (12). Therefore, it was conceivable that SPARC represents a key EMT modulator in the context of the interactions between cancer cells and MSCs. Therefore, the present study focused on SPARC expression in cancer cells induced by interactions with MSCs.

Previous studies have reported the upregulation of SPARC expression in cells from different types of cancer, including gastric cancer (39), pancreatic cancer (40) and CRC (41). However, a conclusive view on its association with prognosis 
Table VIII. Results of animal experiments (orthotopic tumor implantation).

\begin{tabular}{|c|c|c|c|c|c|}
\hline Group & No. & $\begin{array}{l}\text { Body weight, } g \\
\text { (range) }\end{array}$ & $\begin{array}{c}\text { Tumor weight, } g \\
\text { (range) }\end{array}$ & $\begin{array}{l}\text { Lymph node } \\
\text { metastasis, } \mathrm{n}\end{array}$ & $\begin{array}{l}\text { Liver } \\
\text { metastasis, } \mathrm{n}\end{array}$ \\
\hline KM12SM & 9 & $19.8(16.8-22.1)$ & $0.43(0.2-0.8)$ & $4 / 9^{a}$ & $0 / 9$ \\
\hline KM12SM shSPARC & 6 & $21.5(20.5-22.7)$ & $0.33(0.2-0.5)$ & $0 / 6$ & $0 / 6$ \\
\hline $\mathrm{KM} 12 \mathrm{SM}+\mathrm{MSCs}$ & 10 & $17.3(13.8-22.6)^{\mathrm{b}}$ & $0.77(0.3-1.6)^{\mathrm{b}}$ & $9 / 10^{\mathrm{b}}$ & $0 / 10$ \\
\hline KM12SM shSPARC + MSCs & 9 & $21.0(18.0-23.6)$ & $0.43(0.2-1.0)$ & $2 / 9$ & $0 / 9$ \\
\hline
\end{tabular}

${ }^{\mathrm{a} P}<0.05$ vs. KM12SM shSPARC group, values; ${ }^{\mathrm{b}} \mathrm{P}<0.05$ vs. KM12SM shSPARC + MSCs group, values.; MSCs, mesenchymal stem cells; sh, short hairpin RNA; SPARC, secreted protein acidic and rich in cysteine.

A

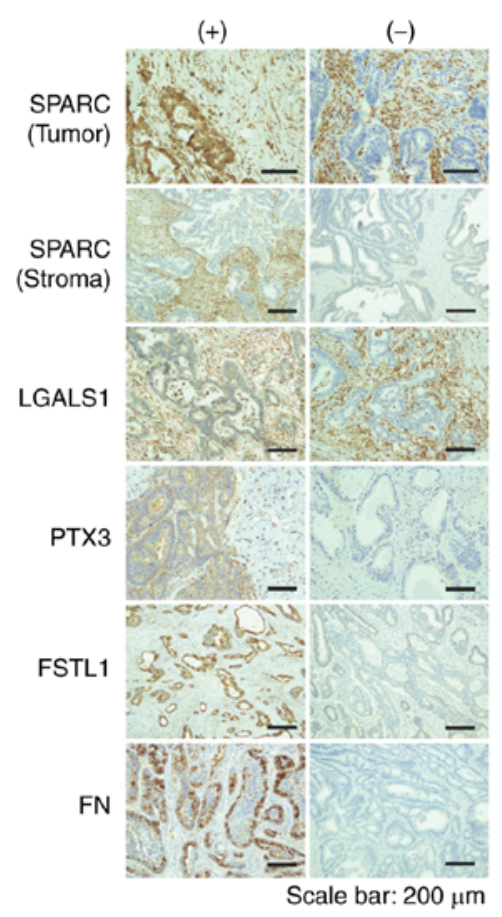

B $(\%)$

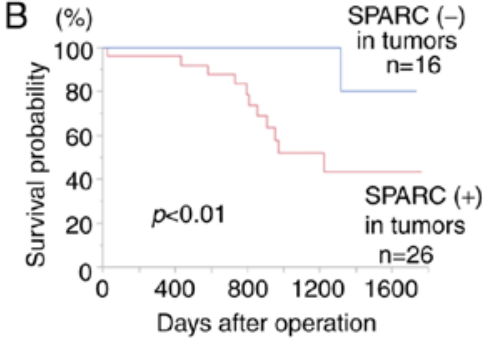

D

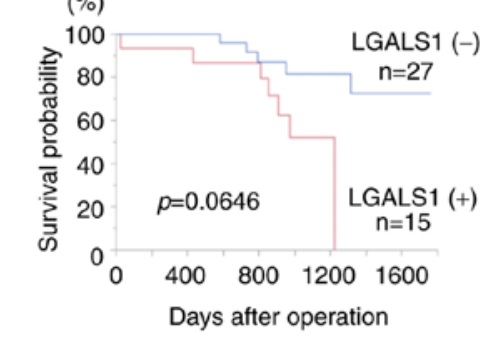

$\mathrm{F}$

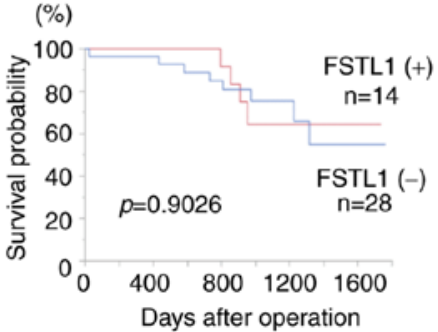

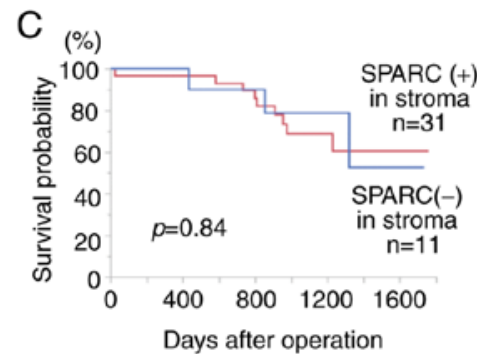

E

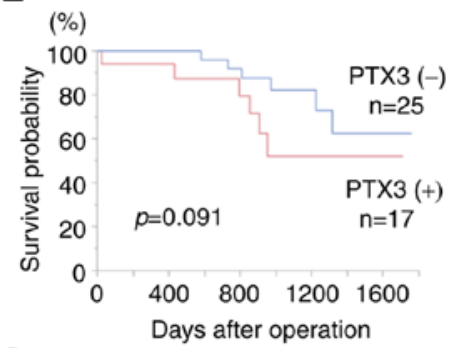

G

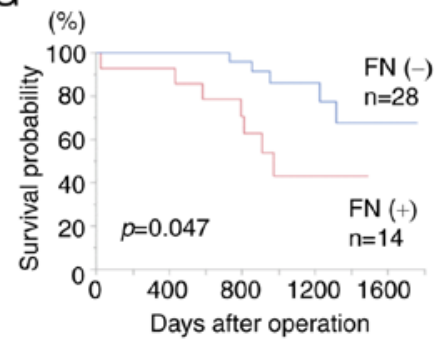

Figure 1. Immunohistochemical analyses of SPARC, LGALS1, PTX3, FSTL1 and FN in surgical specimens from patients with colorectal cancer. (A) Representative images of immunohistochemical staining. Scale bar, $200 \mu \mathrm{m}$. (B) Kaplan-Meier survival curves for patients expressing SPARC in cancer cells compared with the negative group (log-rank test; $\mathrm{P}<0.01)$. (C) Kaplan-Meier survival curves for patients expressing SPARC in stromal cells compared with the negative group. (D) Kaplan-Meier survival curves for LGALS1. (E) Kaplan-Meier survival curves for PTX3. (F) Kaplan-Meier survival curves for FSTL1. (G) Kaplan-Meier survival curves for FN (log-rank test; P<0.05). SPARC, secreted protein acidic and rich in cysteine; LGALS1, galectin-1; PTX3, pentraxin 3; FSTL1, follistatin-related protein 1; FN, fibronectin.

in CRC has not been reached, with a report revealing that SPARC expression in the tumor stroma is associated with poor prognosis (38), while another report has indicated that low expression in the stroma is associated with poor prognosis (42). In the present study, the expression levels of SPARC in cancer cells were associated with the clinicopathological characteristics and prognosis of patients with CRC. Cumulatively, these results suggest that SPARC is an important EMT-related factor involved in the interaction between cancer cells and stromal cells in CRC, and that its expression in cancer cells, not stromal cells, influences tumor progression and prognosis.
However, the association between SPARC expression and prognosis in different tumor types, cell types and populations was inconsistent, indicating the complex role of SPARC in tumor development and metastasis. Therefore, SPARC expression and its functions in CRC remain controversial and, thus, warrant further investigation.

SPARC is a non-structural matrix cell glycoprotein that mediates cell-matrix interactions and serves important roles in wound repair and tissue remodeling $(14,43)$. Additionally, SPARC is involved in cell counter-adhesion, cell proliferation, cell migration and angiogenesis $(14,43)$. SPARC has been 
A

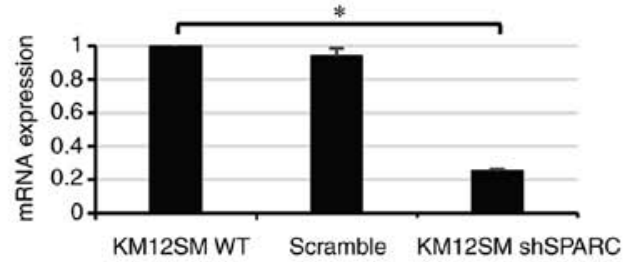

B

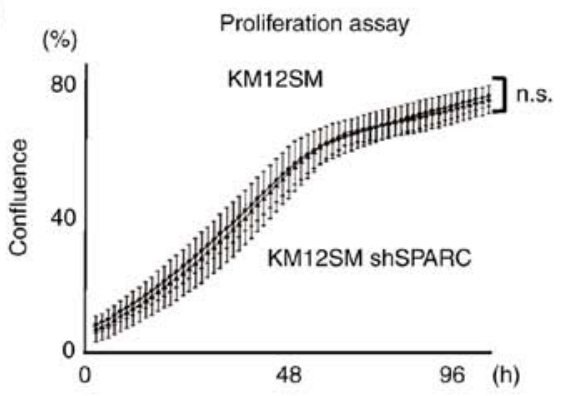

D

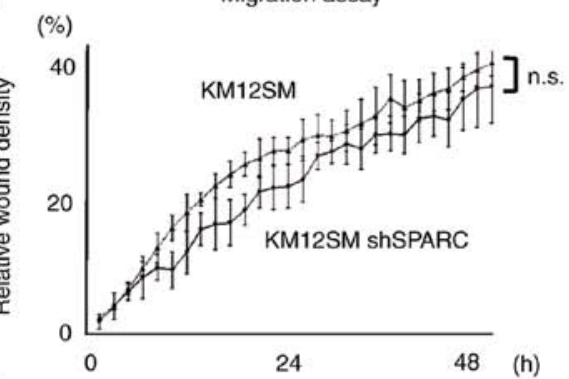

F

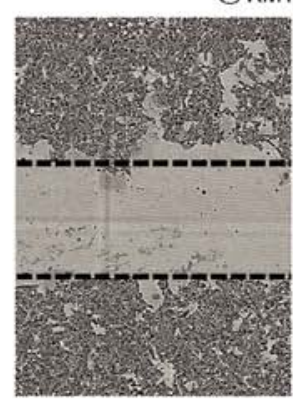

$\mathrm{oh}$

$\mathrm{H}$

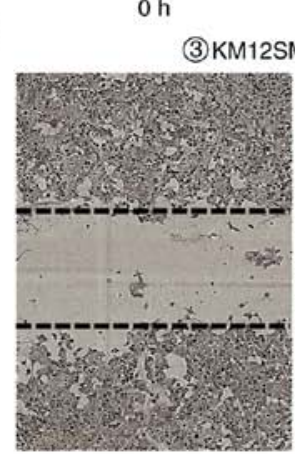

$\mathrm{Oh}$

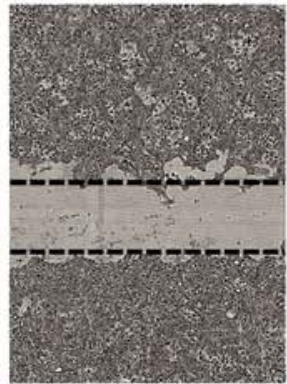

$48 \mathrm{~h}$

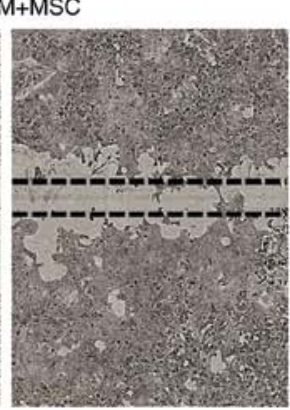

$48 \mathrm{~h}$

C

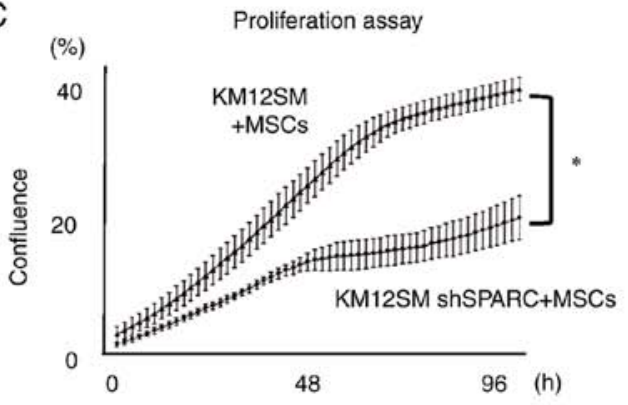

E

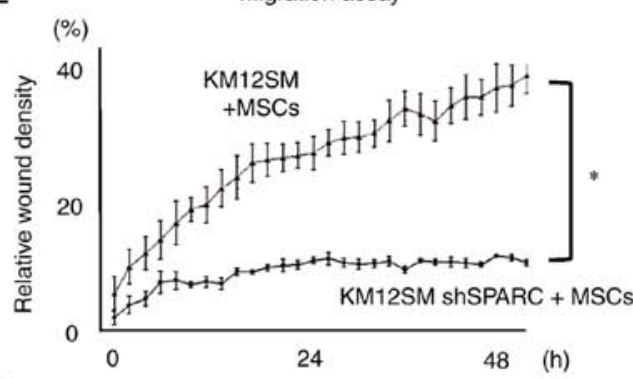

G

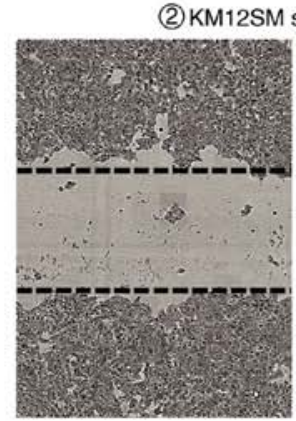

$\mathrm{Oh}$

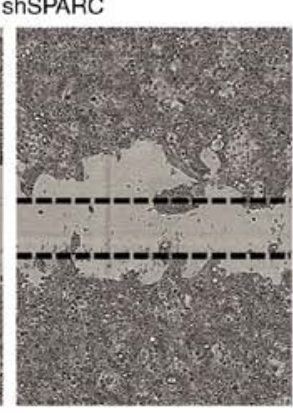

$48 \mathrm{~h}$

I

(4) $\mathrm{KM} 12 \mathrm{SM}$ ShSPARC+MSC

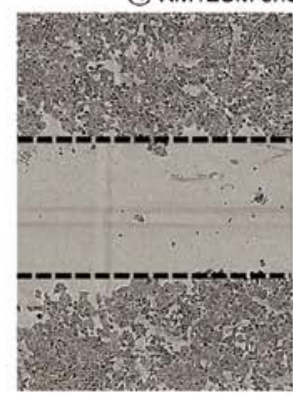

$\mathrm{Oh}$

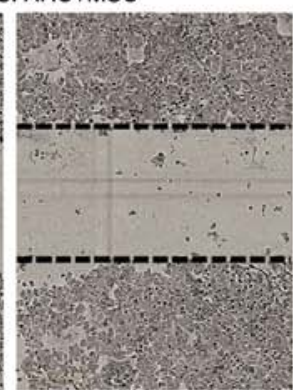

$48 \mathrm{~h}$

Figure 2. Expression levels and function of SPARC in CRC. (A) Gene expression levels of SPARC were downregulated following transfection of KM12SM cells with SPARC shRNA. SPARC mRNA expression in CRC cells was quantified by reverse transcription-quantitative PCR. Data are presented as the mean \pm SEM. ${ }^{*}$ P $<0.05$. (B) Proliferation ability of WT and shSPARC cells when cultured alone. (C) Proliferation ability of WT and shSPARC cells when co-cultured with MSCs. "P<0.05. (D) Migration ability of WT and shSPARC cells when cultured alone. (E) Migration ability of WT and shSPARC cells when co-cultured with MSCs. ${ }^{*} \mathrm{P}<0.05$. (F-I) Representative images of migration assay at 0 and $48 \mathrm{~h}$ (magnification, $\mathrm{x} 10$ ). (F) WT, (G) shSPARC, (H) WT + MSCs and (I) shSPARC + MSCs. CRC, colorectal cancer; MSCs, mesenchymal stem cells; n.s., not significant; sh/shRNA, short hairpin RNA; SPARC, secreted protein acidic and rich in cysteine; WT, wild-type.

demonstrated to promote migration and EMT in highly metastatic cancer types, including prostate cancer and breast cancer $(44,45)$. Furthermore, SPARC has been demonstrated to promote angiogenesis in melanoma (46). Additionally, to 

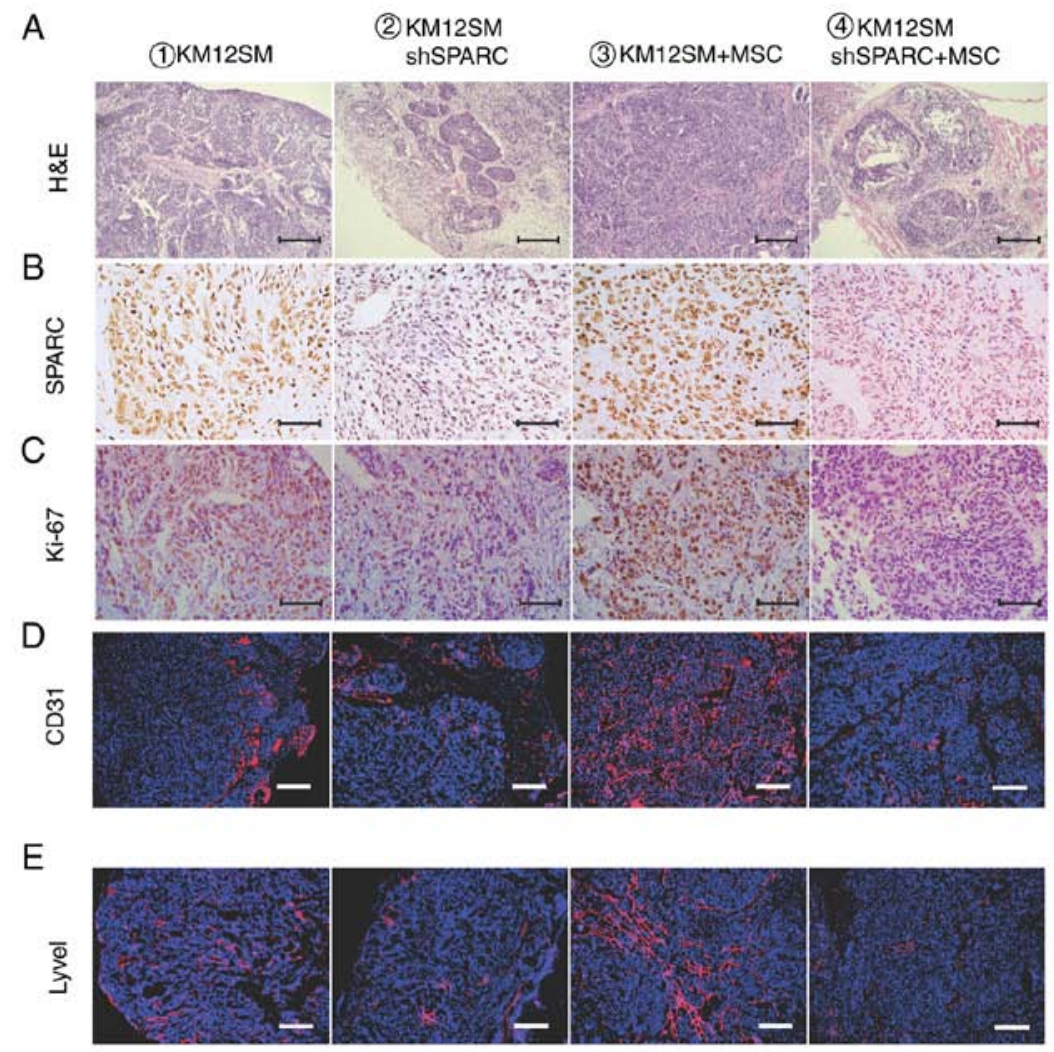

$\mathrm{F}$

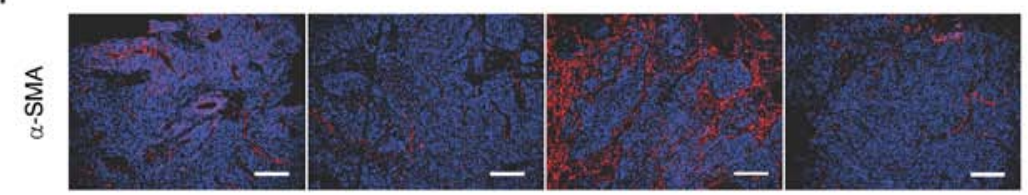

G
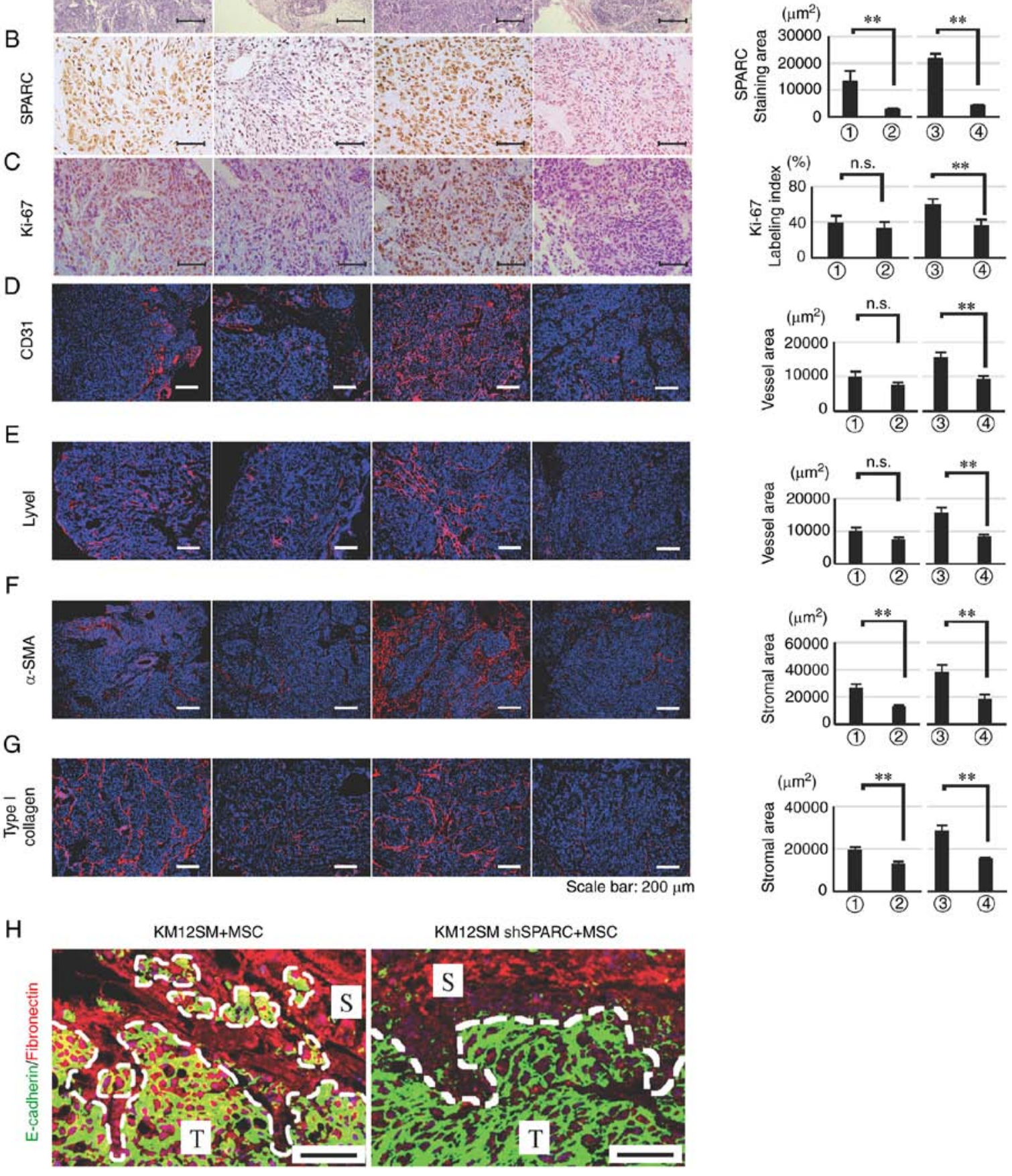

$\mathrm{H}$

Figure 3. Effects of SPARC silencing on orthotopically implanted KM12SM tumor growth. Histological and immunofluorescence staining of orthotopic tumors was performed 42 days after cell implantation. (A) H\&E staining. (B) SPARC expression in tumors transfected with SPARC shRNA. (C-G) Analysis of (C) cell proliferation (Ki-67), (D) angiogenesis (CD31), (E) lymphangiogenesis (Lyvel) and (F and $\mathrm{G})$ the stromal reaction [(F) $\alpha$-SMA and (G) type I collagen]. Red, CD31, Lyve1, $\alpha$-SMA and type I collagen; blue, DAPI. Data are presented as the mean \pm SEM. ${ }^{* *}$ P $<0.01$. Scale bars, $200 \mu \mathrm{m}$ (A and D-G) or $50 \mu \mathrm{m}$ (B and C). (H) Evaluation of epithelial-mesenchymal transition in the tumor edge by double immunofluorescence staining for E-cadherin and fibronectin. Green, E-cadherin; red, fibronectin; blue, DAPI. Scale bars, $200 \mu \mathrm{m}$. T, tumor nest; S, stroma; $\alpha$-SMA, $\alpha$-smooth muscle actin; H\&E, hematoxylin and eosin; Lyve1, lymphatic vessel endothelial hyaluronan receptor 1; MSCs, mesenchymal stem cells; n.s., not significant; sh, short hairpin RNA; SPARC, secreted protein acidic and rich in cysteine.

the best of our knowledge, the effects of SPARC on the tumor microenvironment in CRC have not been reported in detail, and these were assessed in the present study using an orthotopic transplantation model. Histological analysis suggested that SPARC expression in cancer cells was associated with EMT, stromal reactions and angiogenesis. These changes were more pronounced in tumors co-transplanted with MSCs, suggesting that SPARC functions are induced by the 


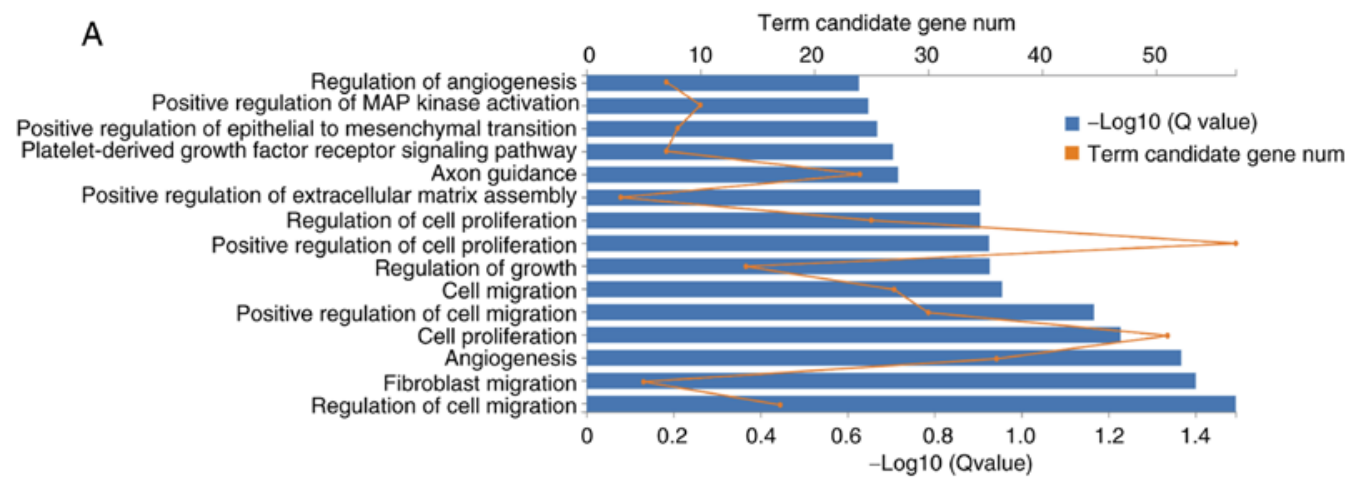

B
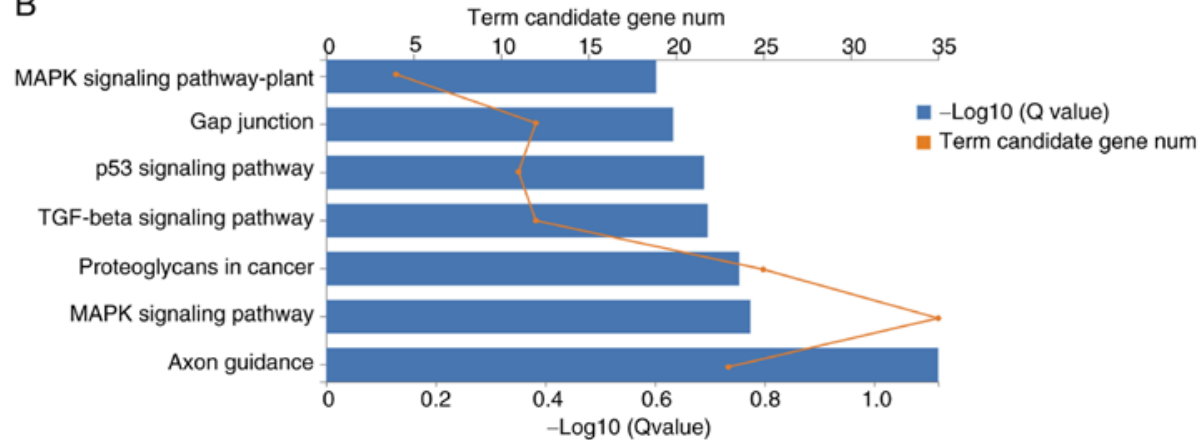

C

Gene sets

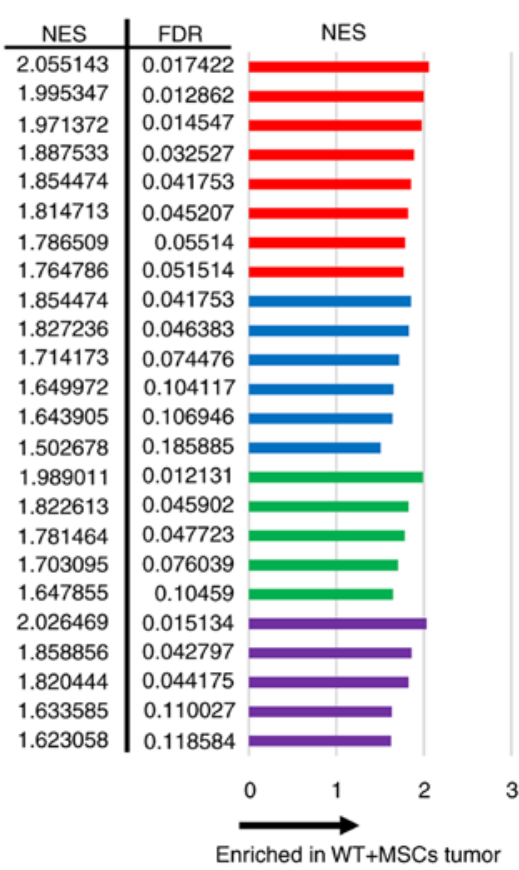

Figure 4. Summary of RNA-sequencing comparison of increased expression for WT + MSCs tumors vs. shSPARC + MSCs tumors. (A) GO biological process enrichment analysis. (B) KEGG pathway analysis. (C) GSEA. Significant changes were defined as a Q-value $<0.25$. Gene sets and pathways associated with proliferation, angiogenesis, stromal reaction and EMT were extracted. GO, Gene Ontology; GSEA, gene set enrichment analysis; KEGG, Kyoto Encyclopedia of Genes and Genomes; MSCs, mesenchymal stem cells; NES, normalized enrichment score; sh, short hairpin RNA; SPARC, secreted protein acidic and rich in cysteine; WT, wild-type.

interaction between cancer cells and stromal cells. Particularly in invasive $\mathrm{CRC}$, which is prone to stromal reactions, cancer and stromal interactions are abundant (47), suggesting a more critical role for SPARC in tumor development and progression. Furthermore, in contrast to the in vitro results, the tendency to suppress angiogenesis and stromal reactions in shSPARC tumors without MSCs may be due to the presence of fibroblasts and migrating MSCs that are physiologically present at the transplantation site in vivo, which may interact with cancer cells and contribute to the formation of the microenvironment.
Consistent with our pathological analysis findings, mRNA sequencing revealed that silencing SPARC in cancer cells attenuated the expression of stromal activated genes, angiogenesis-related genes and cell proliferative genes in tumors. Furthermore, KEGG pathway analysis demonstrated that $S P A R C$ silencing suppressed the axon guidance pathway. Axon guidance has been reported to contribute to tumor microenvironment formation by affecting pericyte, immune response and stromal reaction (48). Furthermore, the MAPK, TGF- $\beta$ and p53 signaling pathways were suppressed by SPARC silencing, 
and all of these are known EMT regulators and are reportedly associated with SPARC expression in glioma, lung cancer and melanoma (15,49-52). GSEA revealed that the expression of gene sets associated with stromal formation, cell proliferation, angiogenesis and EMT was also reduced by SPARC silencing. However, the altered expression levels of genes associated with stromal formation were most pronounced, indicating that SPARC induces EMT with significant involvement in stromal formation in the tumor microenvironment.

Therefore, SPARC may function as an upstream regulator of pathways associated with EMT, thereby affecting tumor infiltration and metastasis. Considering that invasiveness and metastasis of CRC are the primary causes of death, further investigations into the EMT-related genes associated with invasion and metastasis in CRC, including SPARC, remain warranted to elucidate the underlying mechanisms and to identify novel biomarkers for the prevention and treatment of CRC.

In summary, an association was observed between SPARC expression in cancer cells and the clinicopathological characteristics and prognosis of patients with CRC. In shSPARC cells, proliferation and migration abilities were suppressed following co-culture with MSCs. In orthotopic tumors co-transplanted with MSCs, suppression of SPARC expression suppressed growth, stromal reactions and EMT, thus inhibiting the interaction between cancer and stromal cells in the tumor microenvironment. Therefore, SPARC was associated with CRC progression and metastasis, and is a potential effective prognostic marker for CRC that may also serve as a promising target molecule for the development of CRC treatments in the future.

\section{Acknowledgements}

The KM12SM cell line was donated by Dr Isaiah J. Fidler (University of Texas, Houston, TX, USA). Human MSCs were provided by Dr Yukihito Higashi(Department of Cardiovascular Physiology and Medicine, Hiroshima University).

\section{Funding}

The present study was partially supported by the PUH Research Grant Program (advanced research A; no. 01).

\section{Availability of data and materials}

The datasets used and/or analyzed during the current study are available from the corresponding author on reasonable request.

\section{Authors' contributions}

TN performed most of the experiments, analyzed the data and wrote the manuscript. RY, YK and HT designed the experiments and contributed to writing the manuscript. TN and RY confirmed the authenticity of the data. YH prepared the MSCs and contributed to writing the manuscript. TK and KK collected clinical tissue samples and pathological information and contributed to analysis of the clinical data. ST and $\mathrm{KC}$ contributed to the conception and design of the study. All authors discussed the results. All authors read and approved the final manuscript.

\section{Ethics approval and consent to participate}

The protocol was approved by the Ethics Committee of Hiroshima University Graduate School of Medicine (Hiroshima, Japan) and the National Hospital Organization Kure Medical Center (Hiroshima, Japan). All clinical samples were obtained from patients who had provided written informed consent for the use of their tissues for the purposes of research after surgery. The animal experiment was approved by the Committee on Animal Experimentation of Hiroshima University (Hiroshima, Japan).

\section{Patient consent for publication}

Not applicable.

\section{Competing interests}

The authors declare that they have no competing interests.

\section{References}

1. Jemal A, Bray F, Center MM, Ferlay J, Ward E and Forman D: Global cancer statistics. CA Cancer J Clin 61: 69-90, 2011.

2. Marmol I, Sanchez-de-Diego C, Pradilla Dieste A, Cerrada E and Rodriguez Yoldi MJ: Colorectal carcinoma: A general overview and future perspectives in colorectal cancer. Int J Mol Sci 18: 197, 2017.

3. Ng L, Poon RT and Pang R: Biomarkers for predicting future metastasis of human gastrointestinal tumors. Cell Mol Life Sci 70: 3631-3656, 2013.

4. Yue B: Biology of the extracellular matrix: An overview. J Glaucoma 23 (Suppl 1): S20-S23, 2014.

5. Whiteside TL: The tumor microenvironment and its role in promoting tumor growth. Oncogene 27: 5904-5912, 2008.

6. Mantovani A, Allavena P, Sica A and Balkwill F: Cancer-related inflammation. Nature 454: 436-444, 2008.

7. De Wever O and Mareel M: Role of tissue stroma in cancer cell invasion. J Pathol 200: 429-447, 2003.

8. Kalluri R and Zeisberg M: Fibroblasts in cancer. Nat Rev Cancer 6: 392-401, 2006.

9. Kitadai Y, Sasaki T, Kuwai T, Nakamura T, Bucana CD and Fidler IJ: Targeting the expression of platelet-derived growth factor receptor by reactive stroma inhibits growth and metastasis of human colon carcinoma. Am J Pathol 169: 2054-2065, 2006.

10. Wang X, Zhang W, Sun X, Lin Y and Chen W: Cancer-associated fibroblasts induce epithelial-mesenchymal transition through secreted cytokines in endometrial cancer cells. Oncol Lett 15: 5694-5702, 2018

11. Shinagawa K, Kitadai Y, Tanaka M, Sumida T, Kodama M, Higashi Y, Tanaka S, Yasui W and Chayama K: Mesenchymal stem cells enhance growth and metastasis of colon cancer. Int J Cancer 127: 2323-2333, 2010.

12. Takigawa H, Kitadai Y, Shinagawa K, Yuge R, Higashi Y, Tanaka S, Yasui W and Chayama K: Mesenchymal stem cells induce epithelial to mesenchymal transition in colon cancer cells through direct cell-to-cell contact. Neoplasia 19: 429-438, 2017.

13. Nieto MA: Epithelial plasticity: A common theme in embryonic and cancer cells. Science 342: 1234850, 2013.

14. Bradshaw AD and Sage EH: SPARC, a matricellular protein that functions in cellular differentiation and tissue response to injury. J Clin Investig 107: 1049-1054, 2001.

15. Schultz C, Lemke N, Ge S, Golembieski WA and Rempel SA: Secreted protein acidic and rich in cysteine promotes glioma invasion and delays tumor growth in vivo. Cancer Res 62: 6270-6277, 2002.

16. Massi D, Franchi A, Borgognoni L, Reali UM and Santucci M: Osteonectin expression correlates with clinical outcome in thin cutaneous malignant melanomas. Hum Pathol 30: 339-344, 1999.

17. Yamanaka M, Kanda K, Li NC, Fukumori T, Oka N, Kanayama HO and Kagawa S: Analysis of the gene expression of SPARC and its prognostic value for bladder cancer. J Urol 166: 2495-2499, 2001 
18. Yang E, Kang HJ, Koh KH, Rhee H, Kim NK and Kim H: Frequent inactivation of SPARC by promoter hypermethylation in colon cancers. Int J Cancer 121: 567-575, 2007.

19. Cheetham S, Tang MJ, Mesak F, Kennecke H, Owen D and Tai IT: SPARC promoter hypermethylation in colorectal cancers can be reversed by 5-Aza-2' deoxycytidine to increase SPARC expression and improve therapy response. Br J Cancer 98: 1810-1819, 2008.

20. Ministry of Education, Culture, Sports, Science and Technology, Ministry of Health, Labour and Welfare, Ministry of Economy, Trade and Industry; Ethics Guidelines for Human Genome/Gene Analysis Research. https://www.lifescience.mext.go.jp/files/ pdf/40_213.pdf.

21. Morikawa K, Walker SM, Nakajima M, Pathak S, Jessup JM and Fidler IJ: Influence of organ environment on the growth, selection, and metastasis of human colon carcinoma cells in nude mice. Cancer Res 48: 6863-6871, 1988.

22. Santa María L, Rojas CV and Minguell JJ: Signals from damaged but not undamaged skeletal muscle induce myogenic differentiation of rat bone-marrow-derived mesenchymal stem cells. Exp Cell Res 300: 418-426, 2004.

23. Ishii M, Koike C, Igarashi A, Yamanaka K, Pan H, Higashi Y, Kawaguchi H, Sugiyama M, Kamata N, Iwata T, et al: Molecular markers distinguish bone marrow mesenchymal stem cells from fibroblasts. Biochem Biophys Res Commun 332: 297-303, 2005.

24. Tsutsumi S, Shimazu A, Miyazaki K, Pan H, Koike C, Yoshida E, Takagishi K and Kato Y: Retention of multilineage differentiation potential of mesenchymal cells during proliferation in response to FGF. Biochem Biophys Res Commun 288: 413-419, 2001.

25. Livak KJ and Schmittgen TD: Analysis of relative gene expression data using real-time quantitative PCR and the 2(-Delta Delta C(T)) method. Methods 25: 402-408, 2001

26. Shinagawa K, Kitadai Y, Tanaka M, Sumida T, Onoyama M, Ohnishi M, Ohara E, Higashi Y, Tanaka S, Yasui W and Chayama K: Stroma-directed imatinib therapy impairs the tumor-promoting effect of bone marrow-derived mesenchymal stem cells in an orthotopic transplantation model of colon cancer. Int J Cancer 132: 813-823, 2013.

27. Kawai S, Takagi Y, Kaneko S and Kurosawa T: Effect of three types of mixed anesthetic agents alternate to ketamine in mice. Exp Anim 60: 481-487, 2011.

28. Chin D, Boyle GM, Williams RM, Ferguson K, Pandeya N, Pedley J, Campbell CM, Theile DR, Parsons PG and Coman WB: Novel markers for poor prognosis in head and neck cancer. Int J Cancer 113: 789-797, 2005.

29. Han W, Cao F, Chen MB, Lu RZ, Wang HB, Yu M, Shi CT and Ding HZ: Prognostic value of SPARC in patients with pancreatic cancer: A systematic review and meta-analysis. PLoS One 11: e0145803, 2016.

30. Gu C, Wang X, Long $\mathrm{T}$, Wang $\mathrm{X}$, Zhong $\mathrm{Y}, \mathrm{Ma} \mathrm{Y}, \mathrm{Hu} \mathrm{Z}$ and Li Z: FSTL1 interacts with VIM and promotes colorectal cancer metastasis via activating the focal adhesion signalling pathway. Cell Death Dis 9: 654, 2018.

31. Sipos B, Hahn D, Carceller A, Piulats J, Hedderich J, Kalthoff H, Goodman SL, Kosmahl M and Klöppel G: Immunohistochemical screening for beta6-integrin subunit expression in adenocarcinomas using a novel monoclonal antibody reveals strong up-regulation in pancreatic ductal adenocarcinomas in vivo and in vitro. Histopathology 45: 226-236, 2004.

32. Kim D, Langmead B and Salzberg SL: HISAT: A fast spliced aligner with low memory requirements. Nat Methods 12: $357-360,2015$

33. Langmead B and Salzberg SL: Fast gapped-read alignment with Bowtie 2. Nat Methods 9: 357-359, 2012.

34. Li B and Dewey CN: RSEM: Accurate transcript quantification from RNA-Seq data with or without a reference genome. BMC Bioinformatics 12: 323, 2011

35. McKenna A, Hanna M, Banks E, Sivachenko A, Cibulskis K, Kernytsky A, Garimella K, Altshuler D, Gabriel S, Daly M and DePristo MA: The genome analysis toolkit: A MapReduce framework for analyzing next-generation DNA sequencing data. Genome Res 20: 1297-1303, 2010.
36. Shen S, Park JW, Lu ZX, Lin L, Henry MD, Wu YN, Zhou Q and Xing Y: rMATS: Robust and flexible detection of differential alternative splicing from replicate RNA-Seq data. Proc Natl Acad Sci USA 111: E5593-E5601, 2014.

37. Subramanian A, Tamayo P, Mootha VK, Mukherjee S, Ebert BL, Gillette MA, Paulovich A, Pomeroy SL, Golub TR, Lander ES and Mesirov JP: Gene set enrichment analysis: A knowledge-based approach for interpreting genome-wide expression profiles. Proc Natl Acad Sci USA 102: 15545-15550, 2005.

38. Kim JY, Jeong D, Ahn TS, Kim HJ, Park DS, Park SY, Bae SB, Lee S, Lee SS, Lee MS, et al: Expression of secreted protein acidic and rich in cysteine in the stroma of a colorectal carcinoma is associated with patient prognosis. Ann Coloproctol 29: 93-99, 2013.

39. Wang CS, Lin KH, Chen SL, Chan YF and Hsueh S: Overexpression of SPARC gene in human gastric carcinoma and its clinic-pathologic significance. Br J Cancer 91: 1924-1930, 2004.

40. Guweidhi A, Kleeff J, Adwan H, Giese NA, Wente MN, Giese T, Büchler MW, Berger MR and Friess H: Osteonectin influences growth and invasion of pancreatic cancer cells. Ann Surg 242: 224-234, 2005.

41. Porte H, Chastre E, Prevot S, Nordlinger B, Empereur S, Basset P, Chambon P and Gespach C: Neoplastic progression of human colorectal cancer is associated with overexpression of the stromelysin-3 and BM-40/SPARC genes. Int J Cancer 64: 70-75, 1995.

42. Liang JF, Wang HK, Xiao H, Li N, Cheng CX, Zhao YZ, Ma YB, Gao JZ, Bai RB and Zheng HX: Relationship and prognostic significance of SPARC and VEGF protein expression in colon cancer. J Exp Clin Cancer Res 29: 71, 2010.

43. Yan Q and Sage EH: SPARC, a matricellular glycoprotein with important biological functions. J Histochem Cytochem 47: 1495-1506, 1999.

44. Feng $\mathbf{J}$ and Tang L: SPARC in tumor pathophysiology and as a potential therapeutic target. Curr Pharm Des 20: 6182-6190, 2014.

45. Sharma S, Xing F, Liu Y, Wu K, Said N, Pochampally R, Shiozawa Y, Lin HK, Balaji KC and Watabe K: Secreted protein acidic and rich in cysteine (SPARC) mediates metastatic dormancy of prostate cancer in bone. J Biol Chem 291: 19351-19363, 2016.

46. Ordonez JL, Paraoan L, Hiscott P, Gray D, García-Fiñana M, Grierson I and Damato B: Differential expression of angioregulatory matricellular proteins in posterior uveal melanoma. Melanoma Res 15: 495-502, 2005.

47. Takigawa H, Kitadai Y, Shinagawa K, Yuge R, Higashi Y, Tanaka S, Yasui W and Chayama K: Multikinase inhibitor regorafenib inhibits the growth and metastasis of colon cancer with abundant stroma. Cancer Sci 107: 601-608, 2016

48. Boneschansker L, Nakayama H, Eisenga M, Wedel J, Klagsbrun M, Irimia D and Briscoe DM: Netrin-1 Augments chemokinesis in $\mathrm{CD}^{+} \mathrm{T}$ cells in vitro and elicits a proinflammatory response in vivo. J Immunol 197: 1389-1398, 2016.

49. Sun W, Feng J, Yi Q, Xu X, Chen Y and Tang L: SPARC acts as a mediator of TGF- $\beta 1$ in promoting epithelial-to-mesenchymal transition in A549 and H1299 lung cancer cells. Biofactors 44: 453-464, 2018

50. Fenouille N, Tichet M, Dufies M, Pottier A, Mogha A, Soo JK, Rocchi S, Mallavialle A, Galibert MD, Khammari A, et al: The epithelial-mesenchymal transition (EMT) regulatory factor SLUG (SNAI2) is a downstream target of SPARC and AKT in promoting melanoma cell invasion. PLoS One 7: e40378, 2012.

51. Chen J, Ji T, Wu D, Jiang S, Zhao J, Lin H and Cai X: Human mesenchymal stem cells promote tumor growth via MAPK pathway and metastasis by epithelial mesenchymal transition and integrin alpha5 in hepatocellular carcinoma. Cell Death Dis 10: $425,2019$.

52. Chen L, Guo P, He Y, Chen Z, Chen L, Luo Y, Qi L, Liu Y, Wu Q, Cui Y, et al: HCC-derived exosomes elicit HCC progression and recurrence by epithelial-mesenchymal transition through MAPK/ERK signalling pathway. Cell Death Dis 9: 513, 2018.

This work is licensed under a Creative Commons Attribution-NonCommercial-NoDerivatives 4.0 International (CC BY-NC-ND 4.0) License. 